\title{
$\begin{array}{r}\text { WAGENINGEN } \\ \text { UNIVERSITY \& RESEARCH } \\ \hline\end{array}$
}

\section{The role of n-3 PUFA-derived fatty acid derivatives and their oxygenated metabolites in the modulation of inflammation}

de Bus, I., Witkamp, R., Zuilhof, H., Albada, B., \& Balvers, M.

This is a "Post-Print" accepted manuscript, which has been Published in "Prostaglandins and Other Lipid Mediators"

This version is distributed under a non-commercial no derivatives Creative Commons (C)) $(1) \Theta($ ) $(\mathrm{CC}-\mathrm{BY}-\mathrm{NC}-\mathrm{ND})$ user license, which permits use, distribution, and reproduction in any medium, provided the original work is properly cited and not used for commercial purposes. Further, the restriction applies that if you remix, transform, or build upon the material, you may not distribute the modified material.

Please cite this publication as follows:

de Bus, I., Witkamp, R., Zuilhof, H., Albada, B., \& Balvers, M. (2019). The role of $n-3$ PUFA-derived fatty acid derivatives and their oxygenated metabolites in the modulation of inflammation. Prostaglandins and Other Lipid Mediators, 144, [106351]. https://doi.org/10.1016/j.prostaglandins.2019.106351

You can download the published version at:

https://doi.org/10.1016/j.prostaglandins.2019.106351 


\section{The role of $n-3$ PUFA-derived fatty acid derivatives and their}

\section{oxygenated metabolites in the modulation of inflammation}

Ian de Bus ${ }^{1,2}$, Renger Witkamp ${ }^{1}$, Han Zuilhof ${ }^{2,3,4}$, Bauke Albada ${ }^{2 *}$, Michiel Balvers ${ }^{1 *}$

1) Nutrition and Pharmacology Group, Division of Human Nutrition, Wageningen University \& Research, Stippeneng 4, 6708 WE, Wageningen, The Netherlands

2) Laboratory of Organic Chemistry, Wageningen University \& Research, Stippeneng 4, 6708 WE, Wageningen, The Netherlands

3) School of Pharmaceutical Sciences and Technology, Tianjin University, 92 Weijin Road, Tianjin, P.R. China.

4) Department of Chemical and Materials Engineering, King Abdulaziz University, Jeddah, Saudi Arabia.

*Both authors contributed equally to this manuscript

Corresponding author:

Bauke Albada

Laboratory of Organic Chemistry, Wageningen University \& Research

Stippeneng 4, $6708 \mathrm{WE}$,

Wageningen, The Netherlands

bauke.albada@wur.nl

Tel. +31 (0)317482365

Michiel Balvers

Nutrition and Pharmacology Group,

Division of Human Nutrition

Wageningen University \& Research

Stippeneng 4, $6708 \mathrm{WE}$,

Wageningen, The Netherlands

michiel.balvers@wur.nl

Tel. +31 (0)317482453 


\section{Abstract}

Notwithstanding the ongoing debate on their full potential in health and disease, there is general consensus that $n-3$ PUFAs play important physiological roles. Increasing dietary n-3 PUFA intake results in increased DHA and EPA content in cell membranes as well as an increase in $n-3$ derived oxylipin and -endocannabinoid concentrations, like fatty acid amides and glycerol-esters. These shifts are believed to (partly) explain the pharmacological and anti-inflammatory effects of $n$-3 PUFAs. Recent studies discovered that $n$-3 PUFA-derived endocannabinoids can be further metabolized by the oxidative enzymes CYP-450, LOX and COX, similar to the $n-6$ derived endocannabinoids. Interestingly, these oxidized n-3 PUFA derived endocannabinoids of eicosapentaenoyl ethanolamide (EPEA) and docosahexaenoyl ethanolamide (DHEA) have higher anti-inflammatory and anti-proliferative potential than their precursors. In this review, an overview of recently discovered n-3 PUFA derived endocannabinoids and their metabolites is provided. In addition, the use of chemical probes will be presented as a promising technique to study the $n-3$ PUFA and $n-3$ PUFA metabolism within the field of lipid biochemistry.

\section{Highlights}

- Fatty acid conjugation with amines results in the formation of signalling molecules

- Several of these have immune-modulating, anti-inflammatory properties

- $\quad n$-3 PUFA intake changes circulating PUFA, oxylipin and endocannabinoid profiles

- Oxidized metabolites of DHEA and EPEA are also potentially anti-inflammatory

- Chemical probes can be used to study n-3 PUFA metabolism within lipid biochemistry

\section{Keywords}

PUFA, Endocannabinoid, Inflammation, Oxygenation, Chemical Probes 


\section{Contents}

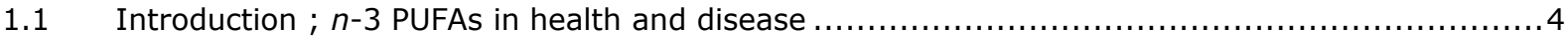

1.2 Lipid metabolite profiles reflect dietary lipid intake: the relation between dietary $n-3$ fatty acid intake and $n-3$ fatty acid derived endocannabinoids

$1.3 n$-3 Fatty acid-derived endocannabinoids: a new mechanistic link between dietary $n-3$ fatty acids and anti-inflammatory effects

1.4 Oxygenation of endocannabinoids: the first evidence of oxygenation of endocannabinoids by CYP450's, LOX, and COX-2 and the anti-inflammatory effects of their metabolites 10

1.5 Oxygenation of $n-3$ PUFA derived endocannabinoids: a new class of endogenous potent antiinflammatory mediators....

1.6 Chemical PUFA and endocannabinoid probes: Development of new chemical tools to study the biological role of endocannabinoids and their anti-inflammatory mechanisms.

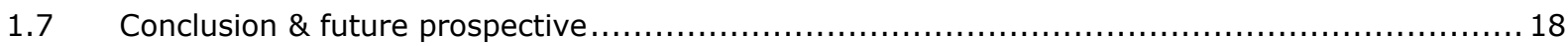

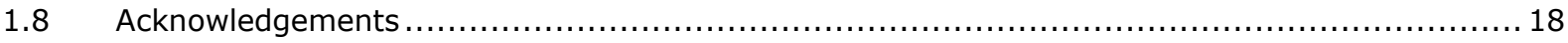

\subsection{Introduction; $n-3$ PUFAs in health and disease}

There is general scientific consensus that $n-3$ long-chain polyunsaturated fatty acids ( $n-3$ LC PUFAs) are essential for normal growth and development of multicellular organisms. Notwithstanding this, the debate on their full potential to prevent or cure disease continues. A major cause of these apparent knowledge gaps is obviously their complex, versatile metabolism, with numerous molecular interconnections to pathways involved in the formation and breakdown of other fatty acids and lipid-derived mediators. Main dietary $n$ 3 LC PUFAs are $\alpha$-linolenic acid (ALA; 18:3n-3), predominantly obtained from plant sources, and eicosapentaenoic acid (EPA; 20:5n-3), docosahexaenoic acid (DHA; 22:6n-3) and, to a lesser extent, docosapentaenoic acid (DPA; 22:5n-3), which are particularly found in "fatty" fish (e.g. herring, salmon, mackerel) as well as in certain algae and krill (Figure 1). In general, ALA can be converted to EPA via elongation of the acyl chain and insertion of extra double bonds via the intermediate stearidonic acid (18:4n3). EPA can be further metabolized to DPA, and finally to DHA. However, in human adults the endogenous conversion of ALA to EPA and DHA is limited, and therefore we rely on dietary intake for the adequate provision of $n$-3 LC PUFAs, or on their administration via food supplements or pharmaceutical preparations ${ }^{1-3}$. Intake of $n$-3 LC PUFAs, in particular DHA and (or) EPA, has been associated with a variety of positive health effects. Examples include improvement of endothelial function ${ }^{4,5}$, lowered plasma triglyceride levels ${ }^{6}$, a reduced risk for ischemic stroke ${ }^{7}$, neuroprotective and antidepressant effects ${ }^{8,9}$, prevention of cognitive decline ${ }^{10}$, positive effects in rheumatoid arthritis ${ }^{11-13}$, fatty liver disease ${ }^{14-17}$, cancer-associated 
cachexia ${ }^{18}$, and a possibly reduced risk for developing certain tumours, in particular colorectal cancer ${ }^{19,20}$. However, these apparently pleiotropic effects are also continuously being challenged, in particular when it comes to cardiovascular health. For example, the originally assumed antiarrhythmic effects of EPA and DHA are also being disputed ${ }^{21}$, and a recent meta-analysis ${ }^{22}$ and Cochrane review ${ }^{23}$ clearly doubted the overall clinical usefulness of $n$-3 PUFAs for prevention of cardiovascular diseases. Data from a number of recently reported randomised collected trials (RCTs) fuelled the debate even more. The Troms $\emptyset$ study found no protective effects of fatty fish consumption or fish oil supplements on atherosclerotic plaque formation or plaque area in a general population ${ }^{24}$. Similarly, the recently reported ASCEND study, an RCT among more than 15,000 patients with diabetes and no evidence of cardiovascular disease taking $460 \mathrm{mg}$ of EPA and $380 \mathrm{mg}$ of DHA for a median of 7 years, showed no significant difference from placebo in the risk of serious vascular events ${ }^{25}$. Another recently finished study, VITAL ${ }^{26,27}$, also indicated that the use of $n-3$ PUFAs was not effective in preventing the combined end point of myocardial infarction, stroke, or death from cardiovascular causes in unselected patients. By contrast, in persons already taking a statin, positive effects of high doses ( $4 \mathrm{~g}$ daily) of EPA on cardiovascular events in the randomized, double-blind REDUCE-IT trial were reported after a median follow-up of 4.9 years ${ }^{27-29}$. Several explanations were offered for these apparent discrepancies. For example, it has been suggested that administered dose, intake and presence of other fatty acids in the diet, like $n-6$ PUFAs, differences between EPA and DHA, and interindividual differences -such as polymorphisms, sex, and age- are also playing a role $27,30-32$.

Mechanistic studies in vitro and in rodent models indicate that many, though perhaps not all, activities of $n-3$ PUFAs found can be linked to their interaction with immunological mechanisms ${ }^{3,8}$. However, amounts used in these studies are often rather high, which complicates extrapolation to humans. Effects on inflammatory markers have been reported from human studies as well, although doses are sometimes high compared to those commonly obtained from the diet. The observed immune-modulating and/or antiinflammatory effects have been explained from different mechanisms, i.e. their effects on cell membranes and modulating eicosanoid production ${ }^{2,3,8}$, interactions with different receptors, including peroxidase proliferator activator receptors (PPARs) [3], FFA 1 [GPR40] ${ }^{33}$, FFA 40 [GPR120] ${ }^{34}$. Highly intriguing, and at the same time further complicating, are the roles of the different intermediates and metabolites of $n$ - 
3 PUFAs. In recent years, different groups have identified various novel classes of endogenously produced n-3 LC PUFA lipid metabolites with potent anti-inflammatory properties. These exciting findings suggest that there are many more lipids present than previously assumed, and future work should shed light on whether these metabolites explain the current controversies around the physiological and pharmacological effects of $n-3$ fatty acids. The aim of this review is to provide an overview of the relation between dietary n-3 fatty acids, primary fatty acid metabolites, recently discovered (secondary) oxygenated lipid metabolites, and their effects on inflammation.

\subsection{Lipid metabolite profiles reflect dietary lipid intake: the relation between dietary $n-3$ fatty acid intake and n-3 fatty acid derived endocannabinoids}

Over the last decades, researchers tried to elucidate the molecular and cellular pathways through which dietary $n-3$ lipids affect health and physiology. A better understanding of the underlying mechanisms could not only help to explain the sometimes apparently contradictory findings, but potentially also provide new targets for intervention. Specifically, it has been demonstrated that $n-3$ fatty acids and their metabolites have various effects on different components of the immune system. For instance, DHA can be converted to resolvins and protectins, a class of lipid metabolites for which potent pro-resolving properties have been described ${ }^{35-38}$. Additionally, work in animal and in vitro models demonstrated that dietary lipids directly affect circulating and tissue concentrations of various oxylipins. Typically, concentrations of $n-6$ fatty acid derived oxylipins, including prostaglandin $\mathrm{D}_{2}\left(\mathrm{PGD}_{2}\right), \mathrm{PGE}_{2}$, thromboxane $\mathrm{B}_{2}\left(\mathrm{TXB}_{2}\right)$ and 5-hydroxyeicosatetraenoic acid (5-HETE) decreased after a diet rich in $n$ 3 fatty acids, whereas higher concentrations of $n-3$ derived oxylipins were detected ${ }^{39-41}$. These $n-3$ derived metabolites were reported to have reduced pro-inflammatory activity compared to their $n-6$ derived counterparts, which could at least partly explain the anti-inflammatory effects observed for $n-3$ fatty acids ${ }^{42}$ (Figure 2). It thus seems clear that circulating profiles of lipid mediators are a reflection of dietary intake of fatty acids, and that high dietary intakes of $n-3$ fatty acids results in measurable changes in the lipidome which may have physiological consequences. 
In addition to oxylipins, many other classes of lipid-derived signalling molecules are known, including ceramides, sphingolipids, and endocannabinoids. The endocannabinoid system consists of the cannabinoid type 1 and type 2 receptors, $\mathrm{CB}_{1}$ and $\mathrm{CB}_{2}$, their endogenous ligands ('endocannabinoids'), and the enzymes involved in the synthesis and metabolism of these molecules ${ }^{43,44}$. It has become clear that the endocannabinoid system is involved in many physiological processes, including metabolism, appetite and the regulation of food intake, differentiation of adipose tissue, and immune regulation. The prototypical endocannabinoid, arachidonoylethanolamine (AEA, also known as anandamide) is the ethanolamide conjugate of arachidonic acid (ARA; 20:4n-6) ${ }^{45}$, but other conjugates of ARA, including 2-arachidonoylglycerol (2-AG) and $\mathrm{N}$-arachidonoyldopamine (NADA) (Figure 3), have also been described to possess affinity for the endocannabinoid receptors ${ }^{43,46}$. In addition to variation in the conjugate group, also the fatty acid backbone is known to vary and conjugates with various fatty acids have been detected in animals or humans such as oleoylethanolamine (OEA), palmitoylethanolamine (PEA), oleoyldopamine (OLDA) or $N$-arachidonoylglycine (NAGly) (Figure 3) ${ }^{47-50}$. Interestingly, similar conjugates derived from DHA and EPA, including docosahexaenoylethanolamine (DHEA), eicosapentaoylethanolamine (EPEA), and eicosapentaoylglycerol (2-EG) have also been detected in animals and humans (Figure 3) ${ }^{49,51-54}$. Considering the number of different dietary fatty acids (e.g. 16:0, C18:0, C18:1n-9, etc.), which can be multiplied by the available endogenous amines (e.g. ethanolamine, dopamine, various amino acids, etc.), potentially $>200$ of these lipid metabolites may be formed. However, thus far only a few of these molecules have received detailed attention, such as AEA, 2-AG, OEA, PEA, DHEA and EPEA. This suggests that only the tip of the iceberg has been explored, and much more remains to be discovered. It is important to note that not all conjugates indicated above have significant affinity for the CB receptors. Instead, these conjugates may activate other receptors such as (PPARs) or transient receptor potential channels (TRPs). Interestingly, these receptors in turn can sometimes also be activated by 'true' endocannabinoids, i.e., ligands of $\mathrm{CB}_{1}$ or $\mathrm{CB}_{2}$ receptors such as AEA ${ }^{43,55,56}$. Taken together, endocannabinoids and their congeners behave as 'promiscuous' ligands, displaying a distinctive pattern of receptor interactions which has been suggested to play a role in 'fine tuning' metabolic and inflammatory regulation [42] 
Indicative of this fine tuning is a recent comparative study on CB and TRPV receptor activation by various $N$-acyl ethanolamines, showing that all $n$-6 PUFA derivatives are agonists of the $\mathrm{CB}_{1}, \mathrm{CB}_{2}$, and $\mathrm{TRPV}_{1}$ receptor, whereas $n-3$ PUFA derivatives are much weaker $\mathrm{CB}_{1}$ and $\mathrm{TRPV}_{1}$ agonists, and equally as effective $\mathrm{CB}_{2}$ agonists ${ }^{57}$.

Studies by our group and others have demonstrated that $n-3$ fatty acids affect the profile of endocannabinoids and related compounds in a way similar as observed for oxylipins ${ }^{58}$. A large body of evidence, comprising of in vitro-, animal- and human data, underlines that increasing the supply of $n-3$ fatty acids results in decreased concentrations of e.g. n-6 PUFA-derived AEA and 2-AG, whereas concentrations of DHEA and EPEA increase ${ }^{51,52,54,59-61}$. This profile shift remained present after an acute inflammatory stimulus with lipopolysaccharide (LPS) in mice ${ }^{52}$. Interestingly, when comparing the immune-modulating properties of DHEA and EPEA with those of their fatty acid precursors and other ethanolamides in an in vitro study, we showed that especially DHEA has more potent antiinflammatory properties compared to e.g. its precursor DHA and its $n-6$ congener AEA ${ }^{62}$. These findings suggest that a shift in endocannabinoid profile is one of the mechanisms behind the proposed health effects of $n-3$ fatty acids (Figure 2).

\section{3 n-3 Fatty acid-derived endocannabinoids: a new mechanistic link between dietary n-3 fatty acids and anti-inflammatory effects}

The two most studied $n-3$ fatty acid-derived endocannabinoids to date are DHEA and EPEA (Figure 3). DHEA was first identified in the bovine retina ${ }^{63}$ and later also in human plasma ${ }^{49}$ and other tissues ${ }^{51}$, 54, 64. Interestingly, this compound has potent anti-inflammatory properties in a variety of models, including stimulated 1) murine RAW264.7 and primary macrophages ${ }^{62}$, 2) murine 3T3-L1 adipocytes ${ }^{53}$, and 3) murine BV2 and rat primary microglial cells ${ }^{65}$. DHEA reduces the release of various proinflammatory signalling molecules, including nitric oxide (NO), interleukin-6 (IL-6), monocyte chemotactic protein-1 (MCP-1), and tumour necrosis factor-alpha (TNF- $\alpha$ ), although differences exist between different in vitro models. Additionally, it was found that DHEA promotes neurogenesis, neuron 
development, and synaptogenesis ${ }^{66-68}$. Because of these properties, DHEA is also referred to as synaptamide ${ }^{66,68}$. In a recent study, the G protein-coupled orphan receptor (GPR110) was found to play a key role in this neuro-protective activity of DHEA by activating a cAMP dependent pathway ${ }^{67,69}$. Moreover, DHEA displays pro-apoptotic and anti-proliferating activity in human prostate cancer cells with considerably increased potency compared to its precursor fatty acid DHA. Less information is available for EPEA, but this conjugate was also found to possess anti-proliferating and pro-apoptotic effects, although with a distinct underlying mechanism compared to DHEA ${ }^{56}$. EPEA also displayed anti-inflammatory properties in macrophages and adipocytes, although with less potency compared to DHEA in macrophages ${ }^{53,62}$. Both DHEA and EPEA are agonists of the CB receptors and of PPAR- $\gamma$, which may mediate the observed anti-inflammatory effects ${ }^{55-57,70}$. To better understand the mechanisms through which DHEA exerts its anti-inflammatory effects in macrophages, detailed in vitro studies were performed, which provided evidence for a direct interaction between DHEA and the cyclooxygenase-2 (COX-2) enzyme ${ }^{71}$. Using a targeted metabolomics approach that quantified various lipid oxygenation metabolites, it was concluded that DHEA specifically reduced the formation of COX-2 derived oxylipins, such as $\mathrm{PGD}_{2}$ and $\mathrm{PGE}_{2}$, whereas other pathways (e.g. 5-lipooxygenase (5-LOX) or cytochrome P450 (CYP450)) were unaffected. These findings suggested that DHEA might act as a direct competitive inhibitor of COX-2 activity. Interestingly, it was previously shown for e.g. AEA and 2-AG that they are COX-2 substrates ${ }^{72,73}$, demonstrating that COX-2 has the capability to metabolize neutral lipids. COX-2 metabolized AEA and 2-AG to oxygenated fatty acid metabolites, such as prostaglandin $\mathrm{E}_{2}$-ethanolamide ( $\left.\mathrm{PGE}_{2}-\mathrm{EA}\right)$ and prostaglandin $\mathrm{E}_{2}$-glycerol $\left(\mathrm{PGE}_{2}-\mathrm{G}\right)$, respectively, which have potent anti-inflammatory properties in vitro ${ }^{74,75}$. In addition to COX-2, other oxidative enzymes such as the lipooxygenases and CYP450 system are capable of metabolizing various fatty acid ethanolamides ${ }^{76}$, including DHEA ${ }^{77-79}$, into oxygenated species which display biological activity themselves (see section 1.5 and Figure 2). It is thus clear that the biological activity of endocannabinoids and related compounds is not only terminated by their enzymatic hydrolysis via fatty acid amide hydrolase (FAAH) or $N$ acylethanolamine-hydrolyzing acid amidase (NAAA) ${ }^{80}$, but that these signalling molecules can also be metabolized by COX-2, LOX and CYP450s to yield a new distinct class of oxygenated fatty acid metabolites with different biological roles. 


\subsection{Oxygenation of endocannabinoids: the first evidence of oxygenation of endocannabinoids by CYP450's, LOX, and COX-2 and the anti-inflammatory effects of their metabolites}

The first evidence of oxygenation of the prototypical endocannabinoid AEA stems from 1995, showing that anandamide is metabolized by CYP450s in both mouse brain and liver microsomes ${ }^{81}$. Although an accurate product analysis was not performed, it was hypothesized that the CYP450 containing microsomes produced various mono-, di-hydroxylated, and epoxidized metabolites of AEA. More recent studies identified all four possible regioisomeric epoxyeicosatrienoic ethanolamides (EET-EAs) and a terminal hydroxylated epoxyeicosatrienoic ethanolamide 20-HETE-EA metabolite of AEA after conversion by various human CYP450s ${ }^{82,83}$. Additionally, it was shown that at least 14,15-EET-EA was produced in bovine and porcine heart microsomes ${ }^{82}$. Similar to the EET-EA production by CYP450 enzymes, it was reported in 1995 that 12-LOX from the rat pineal brain converts AEA into 12-HETEEA, and that soybean 15 -LOX produces 15 -HETE-EA ${ }^{84}$. In 1999, COX-2, was also shown to oxygenate AEA, yielding prostamides (PG-EA's) and the mono-hydroxylated metabolites 11-HETE-EA and 15HETE-EA ${ }^{85,86}$. For the synthesis of the various prostamides known to date, the COX-2 intermediate $\mathrm{PGH}_{2}$-EA is sequentially metabolized by specific prostaglandin synthases to form the biologically active $\mathrm{PGE}_{2}$-EA, $\mathrm{PGD}_{2}$-EA, $\mathrm{PGI}_{2}-\mathrm{EA}^{74,75,87}$, and $\mathrm{PGF}_{2} \alpha$-EA ${ }^{74,75,88}$ (Figure 4). Studies to assess the biological role of some of these prostamides have revealed several potent anti-inflammatory characteristics, specifically for the prostamides $\mathrm{PGF}_{2} \alpha-\mathrm{EA}$ and $\mathrm{PGE}_{2}-\mathrm{EA}$. For example, $\mathrm{PGF}_{2} \alpha$-EA was found to reduce crypt and mucosal tissue damage in a colitis model ${ }^{89}$, and was found to specifically activate the heterodimers of the natural PGF receptor, and one of its splice variants FP- altFP4 ${ }^{75,90}$. PGE 2 -EA reduces the TNF $\alpha$ production in a cAMP-dependent pathway in LPS-stimulated human peripheral blood mononuclear cell monocytes ${ }^{55}$, and inhibits the activity of the IL-12p40 promotor in LPS and INF $\gamma$ stimulated microglia cells ${ }^{91}$ (Figure 4).

Studies investigating receptor affinities of epoxidized AEA metabolites suggested that EET-EAs are potent $\mathrm{CB}$ agonists ${ }^{92}$. Specifically, 5,6-EET-EA has a 300-fold selectivity for $\mathrm{CB}_{2}$ activation over $\mathrm{CB}_{1}$ activation, and a 1000 times increased affinity for $\mathrm{CB}_{2}$ when compared to AEA. Moreover, 5,6-EET- 
EA was shown to be an agonist of the human $\mathrm{CB}_{2}$ receptor ${ }^{93}$. In contrast to the EET-EAs, HETE-EAs display varying affinities towards the $\mathrm{CB}$ receptors. For example, 11-HETE-EA does not interact with $\mathrm{CB}_{1}$ and $\mathrm{CB}_{2}$, whereas 12-HETE-EA is an agonist for both receptors with affinities comparable to AEA ${ }^{94}$. 15-HETE-EA activated $\mathrm{CB}_{1}$ receptors only slightly, but showed strong $\mathrm{TRPV}_{1}$ binding affinity. In view of this $\mathrm{TRPV}_{1}$ activation, it was suggested that 15-HETE-EA caused reduced nociception in a neuropathic pain model ${ }^{95}$. Whether the other HETE-EA are also strong agonists for TRPV1, and also affect neuropathic pain is currently unknown. At the same time, 15-HETE-EA enhanced AEA biosynthesis by NAPE-PLD, and reduced DAGL and FAAH activity. As a result, 15-HETE-EA thus increased AEA tone in mouse brain homogenates ${ }^{96}$ (Figure 4). Like 15-HETE-EA, all other HETEEAs are also known to be inhibitors of FAAH, although with different potencies ${ }^{94}$. Flamand and coworkers speculated that the HETE-EAs mainly exert their biological effect via the vanilloid receptors ${ }^{92}$, although some of them are thus also able to selectively interact with the CBs.

Following the findings that AEA is a substrate for COX-2, LOX and CYP450 enzymes, it was discovered, that other arachidonoyl derivatives are also converted by COX-2, LOX, and CYP450 enzymes ${ }^{74,87,97-99}$. The substrate class now ranges from the classical endocannabinoids like 2-AG and AEA to various amino acid derivatives, like AA-Gly, and different vanilloid derivatives, like NADA. Studies towards the biological activity of some of these other secondary ARA metabolites showed that $\mathrm{PGD}_{2}-\mathrm{G}$, for example, has strong anti-inflammatory effects by reducing the formation of the proinflammatory cytokines in LPS administrated mice ${ }^{100}$, and by reducing DSS induced murine colitis ${ }^{101}$. The 12/15-LOX derived 15-HETE-G was identified as a PPAR $\alpha$ agonist ${ }^{102}$, was found to be a moderate agonist of $\mathrm{CB}_{2}$ and has no affinity with $\mathrm{CB}_{1}{ }^{94,103}$. The CYP450 metabolites $11,12-\mathrm{EET}-\mathrm{G}$, and 14,15EET-G were found to promote vasodilation in rat mesenteric arteries suggesting that they can act as antihypertensive mediators ${ }^{92,103,104}$. Despite these limited data on the physiological role of secondary ARA derived metabolites, there are still many open questions and the extend of this knowledge gap is as yet undefined. More work is needed to fully characterize the metabolism of ARA metabolites and to understand their biological role. 
The identification of the secondary metabolites of ARA and the characterization of their biological activities changed paradigms in the understanding of endocannabinoid biology. Not only the endocannabinoids themselves, but also their oxygenated products must be taken into account when studying the endocannabinoidome ${ }^{44}$, resulting in an additional layer of complexity in the lipid biochemistry field.

\subsection{Oxygenation of n-3 PUFA derived endocannabinoids: a new class of endogenous potent anti-inflammatory mediators}

In addition to oxygenated metabolites of ARA-derived endocannabinoids, evidence is accumulating that DHA and EPA-derived ethanolamides are also substrates for COX-2, LOX and CYP450 enzymes. In this section, we will focus on the formation and inflammatory modulation of recently discovered oxygenated metabolites of DHEA and EPEA.

The first data that demonstrated that DHEA is a substrate for oxidative enzymes was published in 2011 by the group of Serhan and coworkers ${ }^{77}$. In an enzymatic assay with 15-LOX and DHEA they showed that 17-HDHEA was produced as a specific 15-LOX metabolite. In addition, four major 15-LOX derived metabolites, 7,17-diHDHEA, 4,17-diHDHEA 10,17-diHDHEA and 15-HEDPE, were identified in brain tissue ${ }^{77,105}$, of which 10,17-diHDHEA and 15-HEDPEA significantly reduced leukocyte chemotaxis. In addition, 10,17-diHDHEA was observed to block platelet-activator factor (PAF)-stimulated plateletleukocyte aggregation and to stop PMN chemotaxis. 15-HEDPEA was found to stop chemotactic polymorphonuclear leukocyte (PMN) transmigration, to block the PAF-stimulated platelet-leukocyte aggregation, and to significantly reduce PMN accumulation in 6-8 week old male mice with hind limb ischemia and second organ reperfusion injuries. Both 10,17-diHDHEA and 15-HEDPEA were found to activate CB2 receptors. Concluding, both 10,17-diHDHEA and 15-HEDPEA are biologically active anti-inflammatory compounds derived from DHEA ${ }^{77,105}$ (Figure 5, Table 1).

A cell proliferation study showed that DHEA has anti-proliferating properties in head and neck squamous cell carcinoma (HNSCC) cells, dependent on the activity of 5-LOX ${ }^{106}$. By blocking or 
silencing 5-LOX, the HNSCC cells displayed increased proliferative activity, suggesting that 5-LOX mediates the anti-proliferating effects of DHEA. Additionally, data was provided that supported the notion that 5-LOX derived products of DHEA are not directly involved in the mediation of the anticancerous effect, and that the anti-cancerous effects are mainly induced by reactive oxygen species (ROS) formed by 5-LOX. Interestingly, blocking or silencing of COX-2 did not show a COX-2 mediated anti-proliferating effect of DHEA, suggesting that the anti-proliferative effects of DHEA on HNCSS cells are independent of COX-2. On the other hand, results from our group suggested that DHEA might be a substrate for COX-2 in LPS-stimulated RAW 264.7 macrophages (see above) ${ }^{71}$. Current research in our group now focusses on the interaction between DHEA and COX-2.

Das and co-workers demonstrated that both EPEA and DHEA could also be epoxidized by CYP450 to form epoxyeicosatetraenoic acid ethanolamide (EEQ-EA) and epoxydocosapentaenoic acid ethanolamide (EDP-EA), respectively (Figure 5,6, Table 1) ${ }^{78}$. The direct in vitro production of these structures was proven in rat brain microsomes, activated BV-2 microglia cells, and recombinant human CYP2J2 that were incorporated into nanodiscs, which are nanoscale lipid bilayers that are surrounded by a membrane scaffold protein as a model system for membrane proteins ${ }^{107}$. It was found that epoxidation of EPEA and DHEA resulted in the formation of all possible regioisomers, with a preference for the terminal olefin (17,18-EEQ-EA and 19,20-EDP-EA). The terminal regioisomers were tested for their anti-inflammatory properties in BV-2 microglia cells, showing that both 17,18-EEQ-EA and 19,20EDP-EA inhibit NO and IL-6 production, and induce the production of the anti-inflammatory cytokine IL-10. A selective PPAR- $\gamma$ antagonist and $\mathrm{CB}_{2}$ selective antagonist partially reversed the antiinflammatory effects of the epoxide metabolites, indicating that both receptors are involved in the mediation of the anti-inflammatory response. In comparison with EPEA and DHEA, it was found that the epoxide metabolites had increased preferences for $\mathrm{CB}_{2}$ receptor activation. Moreover, 17,18-EEQEA was found to inhibit platelet aggregation, whereas 19,20-EDP-EA showed pro-aggregation effects. Finally, it was found that both 17,18-EEQ-EA and 19,20-EDP-EA have strong anti-angiogenic effects when compared to 17,18-EEQ and 19,20-EDP ${ }^{78}$ (Figure 5,6, Table 1). To study the anti-tumorigenic properties of the EDP-EA structures in more detail, the EDP-EAs were screened for their endogenous 
synthesis and anti-tumorigenic properties in an osteosarcoma model ${ }^{79}$. Various DHEA epoxide derivatives were quantified in metastatic lungs of mice, showing that there was a significant increase of all the epoxide metabolites in the tumorigenic lungs. Of all the EDP-EAs tested, only the 13,14-, 10,11, and 7,8-EDP-EA regioisomers reduced the cell viability and migration behaviour of the tumours. In all tests 10,11-EDP-EA was found to be the most promising anti-tumorigenic metabolite, and was thus selected for more in depth studies. 10,11-EDP-EA did not affect the cell cycle of the osteosarcoma cells, but strongly prevented angiogenesis in a human umbilical vein endothelial cell (HUVEC) cell model. 10,11-EDP-EA was found to activate both the $\mathrm{CB}_{1}$ and $\mathrm{CB}_{2}$ receptor, although it was demonstrated that its anti-tumorigenic properties are not completely mediated by these $\mathrm{CB}$ receptors alone (Figure 5, Table 1). In summary, EEQ-EAs and EDP-EAs have diverse properties when comparing their effects on platelet aggregation and angiogenesis. When concerning their anti-cancerous properties 10,11-EDP-EA thus far shows the most promising results against osteosarcoma. Although there is evidence that the oxidized metabolites of DHEA and EPEA have interesting anti-inflammatory and anti-proliferative effects, these effects were only shown in a limited amount of in vitro studies. As yet, most publications focus on DHEA and their metabolites, and EPEA received less attention. In addition, no reports could be found in the literature that study whether glycerol conjugates of DHA and/or EPA can be metabolized by COX-2. More work is needed to better understand the metabolism of DHEA, EPEA and related congeners by oxidative enzymes, and to evaluate their effectiveness as potential anti-inflammatory and anti-tumorigenic compounds in in vitro and in vivo models.

\subsection{Chemical PUFA and endocannabinoid probes: Development of new chemical tools to study the biological role of endocannabinoids and their anti-inflammatory mechanisms.}

In the previous paragraphs we showed that the endocannabinoidome constitutes a complex interplay between various endocannabinoids, enzymes, and receptors. To be able to better understand the biochemical pathways in the endocannabinoidome and to discover novel therapeutic targets, chemical probes have been particularly useful. Chemical probes always consist of a particular binding or recognition unit, by which the probe mimics its natural biological activity. In addition, the probes also 
always contain a specific chemical handle, which could be a label (for detection) or a 'clickable' group (for click chemistry based detection, visualisation or purification ${ }^{108}$ ). Sometimes probes also contain a crosslinking group, like a diazirine group, that covalently reacts with a biomolecules in close proximity after photo-activation ${ }^{109,}{ }^{110}$. Here we give some examples of PUFA- and endocannabinoid-derived chemical probes that were used to study their molecular interaction targets. All probes have a distinct PUFA or endocannabinoid structure that serves as the basis of the probe. We recognise that next to these PUFA and endocannabinoid derived probes, many groups have focussed on the development of chemical probes for CB receptors ${ }^{110-112}$ and endocannabinoid-related enzymes (like FAAH, NAAA, COX, and LOX, for example) ${ }^{113-116}$. These probes are specifically designed in order to have specific and high binding interactions with their protein target, and do therefore not contain a clear PUFA or endocannabinoid related structure. The probing of endocannabinoid related enzymes is often performed using activity-based profiling. In activity-based profiling the probe contains a chemical reactivity that allows it to covalently bind to the enzyme. Subsequently, the label on the probe is used to visualise or purify the enzyme ${ }^{108}$. The activity-based profiling of 15 -LOX is an excellent example of such a probing methodology ${ }^{115}$. Enzymatic inhibitors are often investigated or screened for by performing a competitive study in the presence of an activity-based probe, resulting in the loss of a specific and detectable interaction between the inhibitor and the enzyme in the cell incubation studies ${ }^{113}$.

\section{Alkyne probes}

The most commonly applied functional group to make probes is the terminal alkyne group $(-\mathrm{C} \equiv \mathrm{CH})$, yielding PUFA or endocannabinoid structures that contain a terminal alkyne that can be coupled to azide-group containing tags by a copper-catalysed 1,3-dipolar cycloaddition. This rapid and highyielding reaction is well-known as one of the first and best described 'click' reactions ${ }^{108,117}$. This alkyneazide reaction is often invoked for the visualization of the probe or for the purification and identification of molecular targets of the probe, such as receptors and enzymes (Figure 7). A recent study towards the role of lipid-derived electrophiles derived from 12/15-LOX made use of such a 19-alkyne-ARA probe (AA-A, Figure 8), to show that $12 / 15$-LOX is mainly involved in the regulation of the central metabolic 
pathway. This was done by converting 19-alkyne-ARA to lipid-derived electrophilic products in peritoneal macrophages, after which the alkynes were coupled to biotinylated azide tags. These products were subsequently purified with streptavidin-coated beads. Proteomic screening then revealed that the lipid-derived electrophiles had strong interactions with proteins from the central metabolic pathway e.g. glycolysis pathway, citric acid cycle, long chain fatty acid beta-oxidation. Additional knockout studies and control experiments showed that 12/15-LOX indeed plays a particular role in the energy metabolism of peritoneal macrophages, like involvement in glycolysis and mitochondrial respiration ${ }^{118}$. A similar study was performed to study the protein targets of stearoyl, palmitoyl, oleoyl, and arachidonoyl ethanolamine derivatives in human embryonic kidney 293 cells (HEK293T), with diazirine and alkyne containing probe molecules ${ }^{109}$ (AEA-DA, AA-DA, Figure 8). Again, proteomic analysis was performed after clicking the alkynes to azide-functionalised biotinylated tags. The diazirine photo-activation was used to crosslink the probes in a controlled way to the proteome of the cells. This dual activity of the photo-activation followed by the selective clicking of the endocannabinoid probes, showed the power to target also unannotated lipid binding proteins, which could be useful in the characterisation of novel (anti-) inflammatory pathways.

Although alkyne probes are powerful handles to study and isolate the fatty acid and endocannabinoid compounds, it should be noted that the alkyne probes do not always give identical biological effects compared to the parent compound of interest. For example, when comparing 19-alkyne-AA with regular AA it was found that only half of the alkyne compound was taken up by Jurkat cells when compared to the AA. Platelets were found to synthesize significantly less LOX and COX-derived products in the presence 19-alkyne-AA compared to AA. Ionophore-stimulated neutrophils produced significantly more 5-LOX products in the presence of the alkyne probe, and one of the AA-derived products leukotriene B4 (LTB4) is 12-fold less potent at stimulating neutrophil migration as a terminal alkyne 119. Concluding, this study showed that the use of alkyne-derived analogues can result in slight mechanistic changes.

\section{Other probes}


To help in the identification of novel receptors of the prostamide $\mathrm{PGE}_{2}-\mathrm{EA}$ and $\mathrm{PGE}_{2}-\mathrm{G}$, both endocannabinoids were synthesized with a terminal azide group or an electrophilic isothiocyanide group, in the laboratory of Makryannis. The isothiocyanide surrogate of $\mathrm{PGE}_{2}$-EA was found to reduce the infiltration of leukocytes in murine peritonitis, thus showing to have retained its expected antiinflammatory properties ${ }^{120}$ (Figure 9). A simultaneous study by the same group showed that chemical modifications of $\mathrm{PGE}_{2}$-EA in both the head and tail group did not alter the biological interactions of the prostamide with the CB receptors and endocannabinoid enzymes. All chemically derived prostamides did not interact with prostaglandin EP receptors or other endocannabinoid related proteins, which is also true for $\mathrm{PGE}_{2}$-EA itself ${ }^{121}$. This indicates that these synthetic derivatives could play a role in the identification of novel prostamide receptors or prostamide-related proteins in the future. Another study investigated the interaction and binding mode of 2-AG and AEA towards the $\mathrm{CB}$ receptors by developing tail and head group-modified endocannabinoids. A biotin moiety was introduced at the terminal end of AEA, or biotin, benzophenone or alkyne moieties were introduced at the ethanolamine end of AEA. All modifications resulted in a complete loss of CB receptor activation. Nonetheless, head group biotinylated 2-AG and 2-arachidonyl glyceryl ether (2-AG-E) did activate CB receptors. Since the biotinylated 2-AG-E probe did show the highest $\mathrm{CB}_{1}$ receptor activation, this probe was subsequently used to visualize $\mathrm{CB}_{1}$ receptors in $\mathrm{CB}_{1}$ transfected mouse hippocampal neuronal cell line HT-22 cells ${ }^{122}$ (Figure 9).

Introduction of labels directly into the structure of PUFAs and endocannabinoids has also been used, in particular for in vivo experiments. For example, radiolabelled DHEA was synthesized to study the metabolic fate of DHEA in the brain. From this study it became clear that in mouse brain homogenates DHEA is almost exclusively converted into more polar phospholipids by FAAH. The study also allowed for quantification of DHEA distribution in specific brain areas, showing the highest concentrations in midbrain, brain stem and hypothalamus, and the lowest in striatum, thalamus and hippocampus ${ }^{123}$. Next to the use of radiolabels, deuterium labels have also been introduced in PUFAs, mainly to probe enzymatic reactions. Deuterium labelling was used to determine the mechanistic details of the COX-2 enzyme $^{124,125}$. 
Although chemically derived PUFAs are powerful tools to explore the complexity of their biological fate, their application should not be used without care due to the delicate tuning of the metabolic pathways for differently structured PUFAs and their derivatives. Therefore their application should always be accompanied with a complete set of control experiments, that should show statistically relevant results.

\subsection{Conclusion \& future prospectives}

As outlined in this review, the endocannabinoidome displays a highly complex interplay between dietary lipids, various enzymes and metabolites, and receptors which play an important role in inflammation. It has become clear that $n-3$ fatty acids can be metabolized by enzymes similar to ARA, but yielding distinct ' $n-3$ ' molecules with unique biological properties and receptor affinities. To date, it has been shown that COX-2, LOX and CYP450s are capable of metabolizing DHEA and EPEA, yielding oxygenated molecules with interesting biological properties. As these $n-3$ metabolites are discovered and characterized, our understanding of lipid biochemistry is increasing. At the same time, with every newly discovered and characterized metabolite, it is becoming increasingly clear that lipid biology is more complex than previously understood. Future work needs to contribute to a better understanding of lipid metabolism, biological mechanisms, and activities of various lipids, particularly $n$-3 LC PUFAderived structures. In this work, there is a great need for "bio-inert" chemical probes that allow for in vitro and in vivo identification and screening of (new) cellular targets. This should lead to a mechanistic explanation of the biological roles of $n$-3 lipid metabolites, and a resolution of the controversies that are currently still surrounding human dietary intervention studies with n-3 LC PUFA.

\subsection{Acknowledgements}

We thank the VLAG Graduate School of Wageningen University and Research for financial support.

The authors declare that there is no conflict of interest. 


\section{Literature}

(1) Brenna, J.T., Salem Jr, N., Sinclair, A.J., and Cunnane, S.C. a-Linolenic acid supplementation and conversion to n-3 long-chain polyunsaturated fatty acids in humans. Prostaglandins, Leukotrienes and Essential Fatty Acids 80(2-3):85-91, 2009.

(2) Calder, P.C. Very long-chain n-3 fatty acids and human health: fact, fiction and the future. Proceedings of the Nutrition Society:1-21, 2017.

(3) Calder, P.C. Omega-3 fatty acids and inflammatory processes: from molecules to man. Biochemical Society Transactions 45(5):1105-15, 2017.

(4) Zehr, K.R., and Walker, M.K. Omega-3 polyunsaturated fatty acids improve endothelial function in humans at risk for atherosclerosis: A review. Prostaglandins \& Other Lipid Mediators 134:131-40, 2018.

(5) Baker, E.J., Yusof, M.H., Yaqoob, P., Miles, E.A., and Calder, P.C. Omega-3 fatty acids and leukocyteendothelium adhesion: Novel anti-atherosclerotic actions. Molecular Aspects of Medicine 64:169-81, 2018.

(6) Bays, H.E., Ballantyne, C.M., Kastelein, J.J., Isaacsohn, J.L., Braeckman, R.A., and Soni, P.N. Eicosapentaenoic acid ethyl ester (AMR101) therapy in patients with very high triglyceride levels (from the Multi-center, plAcebo-controlled, Randomized, double-blINd, 12-week study with an open-label Extension [MARINE] trial). The American journal of cardiology 108(5):682-90, 2011.

(7) Hengeveld, L.M., Praagman, J., Beulens, J.W.J., Brouwer, I.A., van der Schouw, Y.T., and Sluijs, I. Fish consumption and risk of stroke, coronary heart disease, and cardiovascular mortality in a Dutch population with low fish intake. European Journal of Clinical Nutrition 72(7):942-50, 2018.

(8) Layé, S., Nadjar, A., Joffre, C., and Bazinet, R.P. Anti-Inflammatory Effects of Omega-3 Fatty Acids in the Brain: Physiological Mechanisms and Relevance to Pharmacology. Pharmacological Reviews 70(1):12-38, 2018.

(9) Larrieu, T., and Layé, S. Food for Mood: Relevance of Nutritional Omega-3 Fatty Acids for Depression and Anxiety. Frontiers in Physiology 9(1047), 2018.

(10) Cederholm, T. Fish consumption and omega-3 fatty acid supplementation for prevention or treatment of cognitive decline, dementia or Alzheimer's disease in older adults - any news? Current Opinion in Clinical Nutrition \& Metabolic Care 20(2):104-9, 2017.

(11) Proudman, S.M., James, M.J., Spargo, L.D., et al. Fish oil in recent onset rheumatoid arthritis: a randomised, double-blind controlled trial within algorithm-based drug use. Annals of the rheumatic diseases 74(1):89-95, 2015.

(12) Navarini, L., Afeltra, A., Gallo Afflitto, G., and Margiotta, D.P.E. Polyunsaturated fatty acids: any role in rheumatoid arthritis? Lipids in Health and Disease 16(1):197, 2017.

(13) Gioxari, A., Kaliora, A.C., Marantidou, F., and Panagiotakos, D.P. Intake of $\omega-3$ polyunsaturated fatty acids in patients with rheumatoid arthritis: A systematic review and meta-analysis. Nutrition 45(Supplement C):114-24.e4, 2018.

(14) Khadge, S., Sharp, J.G., Thiele, G.M., et al. Dietary omega-3 and omega-6 polyunsaturated fatty acids modulate hepatic pathology. The Journal of Nutritional Biochemistry 52:92-102, 2018.

(15) Nakamoto, K., Shimada, K., Harada, S., Morimoto, Y., Hirasawa, A., and Tokuyama, S. DHA supplementation prevent the progression of NASH via GPR120 signaling. European Journal of Pharmacology 820:31-8, 2018.

(16) Scorletti, E., and Byrne, C.D. Omega-3 fatty acids and non-alcoholic fatty liver disease: Evidence of efficacy and mechanism of action. Molecular Aspects of Medicine, 2018.

(17) Spahis, S., Alvarez, F., Ahmed, N., et al. Non-alcoholic fatty liver disease severity and metabolic complications in obese children: impact of omega-3 fatty acids. The Journal of Nutritional Biochemistry 58:2836, 2018.

(18) Witkamp, R.F., and van Norren, K. Let thy food be thy medicine.... when possible. European Journal of Pharmacology, 2018.

(19) Fuentes, N.R., Kim, E., Fan, Y.-Y., and Chapkin, R.S. Omega-3 fatty acids, membrane remodeling and cancer prevention. Molecular Aspects of Medicine, 2018.

(20) Song, M., Zhang, X., Meyerhardt, J.A., et al. Marine $\omega-3$ polyunsaturated fatty acid intake and survival after colorectal cancer diagnosis. Gut 66(10):1790-6, 2017.

(21) Borghi, C., and Pareo, I. Omega-3 in Antiarrhythmic Therapy. High Blood Pressure \& Cardiovascular Prevention 19(4):207-11, 2012.

(22) Aung, T., Halsey, J., Kromhout, D., et al. Associations of omega-3 fatty acid supplement use with cardiovascular disease risks: Meta-analysis of 10 trials involving 77917 individuals. JAMA Cardiology 3(3):225$33,2018$.

(23) Abdelhamid, A.S., Brown, T.J., Brainard, J.S., et al. Omega-3 fatty acids for the primary and secondary prevention of cardiovascular disease. Cochrane Database of Systematic Reviews(7), 2018.

(24) Johnsen, S.H., Jacobsen, B.K., Brækkan, S.K., Hansen, J.-B., and Mathiesen, E.B. Fish consumption, fish oil supplements and risk of atherosclerosis in the Troms $\varnothing$ study. Nutrition Journal 17(1):56, 2018.

(25) Group, A.S.C., Bowman, L., Mafham, M., et al. Effects of n-3 Fatty Acid Supplements in Diabetes Mellitus. New England Journal of Medicine 379(16):1540-50, 2018.

(26) Manson, J.E., Cook, N.R., Lee, I.M., et al. Marine n-3 Fatty Acids and Prevention of Cardiovascular Disease and Cancer. New England Journal of Medicine 380:23-32, 2018.

(27) Bäck, M., and Hansson, G.K. Omega-3 fatty acids, cardiovascular risk, and the resolution of inflammation. The FASEB Journal 33(2):1536-9, 2019.

(28) Budoff, M., Brent Muhlestein, J., Le, V.T., May, H.T., Roy, S., and Nelson, J.R. Effect of Vascepa (icosapent ethyl) on progression of coronary atherosclerosis in patients with elevated triglycerides (200-499 $\mathrm{mg} / \mathrm{dL}$ ) on statin therapy: Rationale and design of the EVAPORATE study. Clinical cardiology 41(1):13-9, 2018. 
(29) Bhatt, D.L., Steg, P.G., Miller, M., et al. Cardiovascular Risk Reduction with Icosapent Ethyl for Hypertriglyceridemia. The New England journal of medicine, 2018.

(30) Zhuang, P., Wang, W., Wang, J., Zhang, Y., and Jiao, J. Polyunsaturated fatty acids intake, omega6/omega-3 ratio and mortality: Findings from two independent nationwide cohorts. Clinical Nutrition, 2018.

(31) Thota, R.N., Ferguson, J.J.A., Abbott, K.A., Dias, C.B., and Garg, M.L. Science behind the cardiometabolic benefits of omega-3 polyunsaturated fatty acids: biochemical effects vs. clinical outcomes. Food \& Function 9(7):3576-96, 2018.

(32) McManus, S., Tejera, N., Awwad, K., et al. Differential effects of EPA versus DHA on postprandial vascular function and the plasma oxylipin profile in men. Journal of Lipid Research 57(9):1720-7, 2016.

(33) Tan, J.K., McKenzie, C., Mariño, E., Macia, L., and Mackay, C.R. Metabolite-Sensing G Protein-Coupled Receptors-Facilitators of Diet-Related Immune Regulation. Annual Review of Immunology 35(1):371-402,

2017.

(34) Oh, D.Y., Talukdar, S., Bae, E.J., et al. GPR120 Is an Omega-3 Fatty Acid Receptor Mediating Potent Anti-inflammatory and Insulin-Sensitizing Effects. Cell 142(5):687-98, 2010.

(35) Serhan, C., Arita, M., Hong, S., and Gotlinger, K. Resolvins, docosatrienes, and neuroprotectins, novel omega-3-derived mediators, and their endogenous aspirin-triggered epimers. Lipids 39(11):1125-32, 2004.

(36) Calder, P.C. n-3 Polyunsaturated fatty acids, inflammation, and inflammatory diseases. The American Journal of Clinical Nutrition 83(6):S1505-19S, 2006.

(37) Calder, P.C. Marine omega-3 fatty acids and inflammatory processes: Effects, mechanisms and clinical relevance. Biochimica et Biophysica Acta (BBA) - Molecular and Cell Biology of Lipids 1851(4):469-84, 2015.

(38) Serhan, C.N., Chiang, N., and Van Dyke, T.E. Resolving inflammation: dual anti-inflammatory and proresolution lipid mediators. Nature Reviews 8(5):349-61, 2008.

(39) Calder, P.C. Polyunsaturated fatty acids and inflammatory processes: New twists in an old tale. Biochimie 91(6): 791-5, 2009.

(40) Calder, P.C. The relationship between the fatty acid composition of immune cells and their function. Prostaglandins, Leukotrienes and Essential Fatty Acids 79(3-5):101-8, 2009.

(41) Schmitz, G., and Ecker, J. The opposing effects of n-3 and n-6 fatty acids. 47(2):147-55, 2008

(42) Bagga, D., Wang, L., Farias-Eisner, R., Glaspy, J.A., and Reddy, S.T. Differential effects of prostaglandin derived from $w-6$ and $w-3$ polyunsaturated fatty acids on COX-2 expression and IL- 6 secretion. Proceedings of the National Academy of Sciences (PNAS) 100(4):1751-6, 2003.

(43) Pertwee, R.G., Howlett, A.C., Abood, M.E., et al. International Union of Basic and Clinical Pharmacology. LXXIX. Cannabinoid Receptors and Their Ligands: Beyond CB1 and CB2. Pharmacological Reviews 62(4):588-631, 2010.

(44) Witkamp, R. Fatty acids, endocannabinoids and inflammation. European Journal of Pharmacology 785:96-107, 2016

(45) Devane, W.A., Hanus, L., Breuer, A., et al. Isolation and Structure of a Brain Constituent That Binds to the Cannabinoid Receptor. 258(5090):1946-9, 1992.

(46) Fukuda, H., Muromoto, R., Takakura, Y., et al. Design and Synthesis of Cyclopropane Congeners of Resolvin E2, an Endogenous Proresolving Lipid Mediator, as Its Stable Equivalents. Organic Letters $18(24): 6224-7,2016$.

(47) Zoerner, A.A., Gutzki, F.M., Suchy, M.T., et al. Targeted stable-isotope dilution GC-MS/MS analysis of the endocannabinoid anandamide and other fatty acid ethanol amides in human plasma. Journal of Chromatography B 877(26):2909-23, 2009.

(48) Bradshaw, H.B., Rimmerman, N., Krey, J.F., and Walker, J.M. Sex and hormonal cycle differences in rat brain levels of pain-related cannabimimetic lipid mediators. Am J Physiol Regul Integr Comp Physiol 291(2):R349-R58, 2006.

(49) Wood, J.T., Williams, J.S., Pandarinathan, L., et al. Comprehensive profiling of the human circulating endocannabinoid metabolome: clinical sampling and sample storage parameters. Clinical Chemistry and Laboratory Medicine 46(9):1289-95, 2008.

(50) Balvers, M.G.J., Verhoeckx, K.C.M., and Witkamp, R.F. Development and validation of a quantitative method for the determination of 12 endocannabinoids and related compounds in human plasma using liquid chromatography-tandem mass spectrometry. Journal of Chromatography B 877(14-15):1583-90, 2009.

(51) Wood, J.T., Williams, J.S., Pandarinathan, L., Janero, D.R., Lammi-Keefe, C.J., and Makriyannis, A. Dietary docosahexaenoic acid supplementation alters select physiological endocannabinoid-system metabolites in brain and plasma. Journal of Lipid Research 51(6):1416-23, 2010.

(52) Balvers, M.G.J., Verhoeckx, K.C.M., Bijlsma, S., et al. Fish oil and inflammatory status alter the n-3 to $\mathrm{n}-6$ balance of the endocannabinoid and oxylipin metabolomes in mouse plasma and tissues. Metabolomics 8(6): 1130-47, 2012

(53) Balvers, M.G.J., Verhoeckx, K.C.M., Plastina, P., Wortelboer, H.M., Meijerink, J., and Witkamp, R.F. Docosahexaenoic acid and eicosapentaenoic acid are converted by 3T3-L1 adipocytes to $\mathrm{N}$-acyl ethanolamines with anti-inflammatory properties. Biochimica et Biophysica Acta (BBA) - Molecular and Cell Biology of Lipids 1801(10):1107-14, 2010.

(54) Artmann, A., Petersen, G., Hellgren, L.I., et al. Influence of dietary fatty acids on endocannabinoid and $\mathrm{N}$-acylethanolamine levels in rat brain, liver and small intestine. Biochimica et Biophysica Acta (BBA) Molecular and Cell Biology of Lipids 1781(4):200-12, 2008.

(55) Brown, I., Cascio, M.G., Rotondo, D., Pertwee, R.G., Heys, S.D., and Wahle, K.W.J. Cannabinoids and omega-3/6 endocannabinoids as cell death and anticancer modulators. Progress in Lipid Research 52(1):80 $109,2013$.

(56) Brown, I., Cascio, M.G., Wahle, K.W.J., et al. Cannabinoid receptor-dependent and -independent antiproliferative effects of omega-3 ethanolamides in androgen receptor-positive and -negative prostate cancer cel lines. Carcinogenesis 31(9):1584-91, 2010. 
(57) Alharthi, N., Christensen, P., Hourani, W., et al. $\mathrm{n}-3$ polyunsaturated $\mathrm{N}$-acylethanolamines are CB2 cannabinoid receptor-preferring endocannabinoids. Biochimica et Biophysica Acta (BBA) - Molecular and Cell Biology of Lipids 1863(11):1433-40, 2018.

(58) Hansen, H.S., and Artmann, A. Endocannabinoids and Nutrition. Journal of Neuroendocrinology 20(1):94-9, 2008.

(59) Berger, A., Crozier, G., Bisogno, T., Cavaliere, P., Innis, S., and Di Marzo, V. Anandamide and diet: Inclusion of dietary arachidonate and docosahexaenoate leads to increased brain levels of the corresponding $\mathrm{N}$ acylethanolamines in piglets. Proceedings of the National Academy of Sciences (PNAS) 98(11):6402-6, 2001. (60) Watanabe, S., Doshi, M., and Hamazaki, T. n-3 Polyunsaturated fatty acid (PUFA) deficiency elevates and n-3 PUFA enrichment reduces brain 2-arachidonoylglycerol level in mice. Prostaglandins, Leukotrienes and Essential Fatty Acids 69(1):51-9, 2003

(61) Matias, I., Carta, G., Murru, E., Petrosino, S., Banni, S., and Di Marzo, V. Effect of polyunsaturated fatty acids on endocannabinoid and $\mathrm{N}$-acyl-ethanolamine levels in mouse adipocytes. Biochimica et Biophysica Acta (BBA) - Molecular and Cell Biology of Lipids 1781(1-2):52-60, 2008.

(62) Meijerink, J., Plastina, P., Vincken, J.-P., et al. The ethanolamide metabolite of DHA, docosahexaenoylethanolamine, shows immunomodulating effects in mouse peritoneal and RAW264.7 macrophages: evidence for a new link between fish oil and inflammation. British Journal of Nutrition 105(12):1798-807, 2011.

(63) Bisogno, T., Delton-Vandenbroucke, I., Milone, A., Lagarde, M., and Di Marzo, V. Biosynthesis and Inactivation of $\mathrm{N}$-Arachidonoylethanolamine (Anandamide) and $\mathrm{N}$-Docosahexaenoylethanolamine in Bovine Retina. Archives of Biochemistry and Biophysics 370(2):300-7, 1999.

(64) Balvers, M.G.J., Verhoeckx, K.C.M., Meijerink, J., et al. Time-dependent effect of in vivo inflammation on eicosanoid and endocannabinoid levels in plasma, liver, ileum and adipose tissue in C57BL/6 mice fed a fishoil diet. International Immunopharmacology 13(2):204-14, 2012.

(65) Park, T., Chen, H., Kevala, K., Lee, J.-W., and Kim, H.-Y. N-Docosahexaenoylethanolamine ameliorates LPS-induced neuroinflammation via CAMP/PKA-dependent signaling. Journal of Neuroinflammation 13(1):284, 2016.

(66) Kim, H.-Y., and Spector, A.A. Synaptamide, endocannabinoid-like derivative of docosahexaenoic acid with cannabinoid-independent function. Prostaglandins, Leukotrienes and Essential Fatty Acids 88(1):121-5, 2013.

(67) Kim, H.-Y., and Spector, A.A. N-Docosahexaenoylethanolamine: A neurotrophic and neuroprotective metabolite of docosahexaenoic acid. Molecular Aspects of Medicine, 2018.

(68) Kim, H.-Y., Spector, A.A., and Xiong, Z.-M. A synaptogenic amide N-docosahexaenoylethanolamide promotes hippocampal development. Prostaglandins \& Other Lipid Mediators 96(1):114-20, 2011.

(69) Lee, J.-W., Huang, B.X., Kwon, H., et al. Orphan GPR110 (ADGRF1) targeted by Ndocosahexaenoylethanolamine in development of neurons and cognitive function. Nature Communications 7:13123, 2016.

(70) Rovito, D., Giordano, C., Vizza, D., et al. Omega-3 PUFA ethanolamides DHEA and EPEA induce autophagy through PPARY activation in MCF-7 breast cancer cells. Journal of Cellular Physiology 228(6):131422, 2013.

(71) Meijerink, J., Poland, M., Balvers, M.G.J., et al. Inhibition of COX-2-mediated eicosanoid production plays a major role in the anti-inflammatory effects of the endocannabinoid $\mathrm{N}$-docosahexaenoylethanolamine (DHEA) in macrophages. British Journal of Pharmacology 172(1):24-37, 2015.

(72) Rouzer, C.A., and Marnett, L.J. Structural and functional differences between cyclooxygenases: Fatty acid oxygenases with a critical role in cell signaling. Biochemical and Biophysical Research Communications 338(1):34-44, 2005.

(73) Rouzer, C.A., and Marnett, L.J. Non-redundant Functions of Cyclooxygenases: Oxygenation of Endocannabinoids. Journal of Biological Chemistry 283(13):8065-9, 2008

(74) Urquhart, P., Nicolaou, A., and Woodward, D.F. Endocannabinoids and their oxygenation by cyclooxygenases, lipoxygenases and other oxygenases. Biochimica et Biophysica Acta (BBA) - Molecular and Cell Biology of Lipids 1851(4):366-76, 2015.

(75) Alhouayek, M., and Muccioli, G.G. COX-2-derived endocannabinoid metabolites as novel inflammatory mediators. Trends in Pharmacological Sciences 35(6):284-92, 2014.

(76) Rouzer, C.A., and Marnett, L.J. Endocannabinoid Oxygenation by Cyclooxygenases, Lipoxygenases, and Cytochromes P450: Cross-Talk between the Eicosanoid and Endocannabinoid Signaling Pathways. Chemical Reviews 111(10):5899-921, 2011.

(77) Yang, R., Fredman, G., Krishnamoorthy, S., et al. Decoding Functional Metabolomics with Docosahexaenoyl Ethanolamide (DHEA) Identifies Novel Bioactive Signals. Journal of Biological Chemistry 286(36):31532-41, 2011.

(78) McDougle, D.R., Watson, J.E., Abdeen, A.A., et al. Anti-inflammatory $\omega-3$ endocannabinoid epoxides. Proceedings of the National Academy of Sciences 114(30):E6034-E43, 2017.

(79) Roy, J., Watson, J.E., Hong, I.S., Fan, T.M., and Das, A. Antitumorigenic Properties of Omega-3 Endocannabinoid Epoxides. Journal of Medicinal Chemistry, 2018.

(80) Ueda, N., Tsuboi, K., and Uyama, T. Enzymological studies on the biosynthesis of Nacylethanolamines. Biochimica et Biophysica Acta (BBA) - Molecular and Cell Biology of Lipids 1801(12):127485, 2010.

(81) Bornheim, L.M., Kim, K.Y., Chen, B., and Correia, M.A. Microsomal cytochrome P450-mediated liver and brain anandamide metabolism. Biochemical Pharmacology 50(5):677-86, 1995.

(82) McDougle, D.R., Kambalyal, A., Meling, D.D., and Das, A. Endocannabinoids Anandamide and 2Arachidonoylglycerol Are Substrates for Human CYP2J2 Epoxygenase. Journal of Pharmacology and Experimental Therapeutics 351(3):616, 2014. 
(83) Snider, N.T., Kornilov, A.M., Kent, U.M., and Hollenberg, P.F. Anandamide Metabolism by Human Liver and Kidney Microsomal Cytochrome P450 Enzymes to Form Hydroxyeicosatetraenoic and Epoxyeicosatrienoic Acid Ethanolamides. Journal of Pharmacology and Experimental Therapeutics 321(2):590-7, 2007.

(84) Hampson, A.J., Hill, W.A.G., Zan-Phillips, M., et al. Anandamide hydroxylation by brain lipoxygenase:metabolite structures and potencies at the cannabinoid receptor. Biochimica et Biophysica Acta (BBA) - Lipids and Lipid Metabolism 1259(2):173-9, 1995.

(85) Kozak, K.R., Prusakiewicz, J.J., Rowlinson, S.W., Prudhomme, D.R., and Marnett, L.J. Amino Acid Determinants in Cyclooxygenase-2 Oxygenation of the Endocannabinoid Anandamide. Biochemistry 42(30): 9041-9, 2003.

(86) Yu, M., Ives, D., and Ramesha, C.S. Synthesis of Prostaglandin E2 Ethanolamide from Anandamide by Cyclooxygenase-2. Journal of Biological Chemistry 272(34):21181-6, 1997.

(87) Kozak, K.R., Crews, B.C., Morrow, J.D., et al. Metabolism of the Endocannabinoids, 2Arachidonylglycerol and Anandamide, into Prostaglandin, Thromboxane, and Prostacyclin Glycerol Esters and Ethanolamides. Journal of Biological Chemistry 277(47):44877-85, 2002.

(88) Koda, N., Tsutsui, Y., Niwa, H., Ito, S., Woodward, D.F., and Watanabe, K. Synthesis of prostaglandin $\mathrm{F}$ ethanolamide by prostaglandin $\mathrm{F}$ synthase and identification of Bimatoprost as a potent inhibitor of the enzyme: new enzyme assay method using LC/ESI/MS. Archives of Biochemistry and Biophysics 424(2):128-36, 2004.

(89) Nicotra, L.L., Vu, M., Harvey, B.S., and Smid, S.D. Prostaglandin ethanolamides attenuate damage in a human explant colitis model. Prostaglandins \& Other Lipid Mediators 100-101:22-9, 2013.

(90) Woodward, D.F., Wang, J.W., and Poloso, N.J. Recent Progress in Prostaglandin F2a Ethanolamide (Prostamide F2a) Research and Therapeutics. Pharmacological Reviews 65(4):1135-47, 2013.

(91) Correa, F., Docagne, F., Clemente, D., Mestre, L., Becker, C., and Guaza, C. Anandamide inhibits IL12 p40 production by acting on the promoter repressor element GA-12: possible involvement of the COX-2 metabolite prostamide E2. Biochemical Journal 409(3):761, 2008.

(92) Turcotte, C., Chouinard, F., Lefebvre, J.S., and Flamand, N. Regulation of inflammation by cannabinoids, the endocannabinoids 2-arachidonoyl-glycerol and arachidonoyl-ethanolamide, and their metabolites. Journal of Leukocyte Biology 97(6):1049-70, 2015.

(93) Snider, N.T., Nast, J.A., Tesmer, L.A., and Hollenberg, P.F. A cytochrome P450-derived epoxygenated metabolite of anandamide is a potent cannabinoid receptor 2-selective agonist. Molecular pharmacology 75(4):965-72, 2009

(94) van der Stelt, M., van Kuik, J.A., Bari, M., et al. Oxygenated Metabolites of Anandamide and 2Arachidonoylglycerol: Conformational Analysis and Interaction with Cannabinoid Receptors, Membrane Transporter, and Fatty Acid Amide Hydrolase. Journal of Medicinal Chemistry 45(17):3709-20, 2002.

(95) Starowicz, K., Makuch, W., Korostynski, M., et al. Full Inhibition of Spinal FAAH Leads to TRPV1Mediated Analgesic Effects in Neuropathic Rats and Possible Lipoxygenase-Mediated Remodeling of Anandamide Metabolism. PLOS ONE 8(4):e60040, 2013.

(96) Amadio, D., Fezza, F., Catanzaro, G., et al. Methylation and acetylation of 15-hydroxyanandamide modulate its interaction with the endocannabinoid system. Biochimie 92(4):378-87, 2010.

(97) Prusakiewicz, J.J., Turman, M.V., Vila, A., et al. Oxidative metabolism of lipoamino acids and vanilloids by lipoxygenases and cyclooxygenases. Archives of Biochemistry and Biophysics 464(2):260-8, 2007.

(98) Kozak, K.R., Rowlinson, S.W., and Marnett, L.J. Oxygenation of the Endocannabinoid, 2Arachidonylglycerol, to Glyceryl Prostaglandins by Cyclooxygenase-2. Journal of Biological Chemistry 275(43):33744-9, 2000.

(99) Moody, J.S., Kozak, K.R., Ji, C., and Marnett, L.J. Selective Oxygenation of the Endocannabinoid 2Arachidonylglycerol by Leukocyte-Type 12-Lipoxygenase. Biochemistry 40(4):861-6, 2001.

(100) Alhouayek, M., Masquelier, J., Cani, P.D., Lambert, D.M., and Muccioli, G.G. Implication of the antiinflammatory bioactive lipid prostaglandin D2-glycerol ester in the control of macrophage activation and inflammation by ABHD6. Proceedings of the National Academy of Sciences (PNAS) 110(43):17558-63, 2013. (101) Alhouayek, M., Buisseret, B., Paquot, A., Guillemot-Legris, O., and Muccioli, G.G. The endogenous bioactive lipid prostaglandin D2-glycerol ester reduces murine colitis via DP1 and PPARY receptors. The FASEB Journal 32(9):5000-11, 2018.

(102) Kozak, K.R., Gupta, R.A., Moody, J.S., et al. 15-Lipoxygenase Metabolism of 2-Arachidonylglycerol: GENERATION OF A PEROXISOME PROLIFERATOR-ACTIVATED RECEPTOR a AGONIST. Journal of Biological Chemistry 277(26):23278-86, 2002.

(103) Baggelaar, M.P., Maccarrone, M., and van der Stelt, M. 2-Arachidonoylglycerol: A signaling lipid with manifold actions in the brain. Progress in Lipid Research 71:1-17, 2018.

(104) Awumey, E.M., Hill, S.K., Diz, D.I., and Bukoski, R.D. Cytochrome P-450 metabolites of 2arachidonoylglycerol play a role in $\mathrm{Ca} 2+-$ induced relaxation of rat mesenteric arteries. American Journal of Physiology-Heart and Circulatory Physiology 294(5):H2363-H70, 2008.

(105) Shinohara, M., Mirakaj, V., and Serhan, C.N. Functional Metabolomics Reveals Novel Active Products in the DHA Metabolome. Frontiers in Immunology 3:81, 2012.

(106) Park, S.-W., Hah, J.H., Oh, S.-M., Jeong, W.-J., and Sung, M.-W. 5-lipoxygenase mediates docosahexaenoyl ethanolamide and $\mathrm{N}$-arachidonoyl-L-alanine-induced reactive oxygen species production and inhibition of proliferation of head and neck squamous cell carcinoma cells. BMC Cancer 16(1):1-14, 2016. (107) McDougle, D.R., Palaria, A., Magnetta, E., Meling, D.D., and Das, A. Functional studies of N-terminally modified CYP2J2 epoxygenase in model lipid bilayers. Protein science : a publication of the Protein Society 22(7):964-79, 2013.

(108) Best, M.D. Click Chemistry and Bioorthogonal Reactions: Unprecedented Selectivity in the Labeling of Biological Molecules. Biochemistry 48(28):6571-84, 2009.

(109) Niphakis, Micah J., Lum, Kenneth M., Cognetta Iii, Armand B., et al. A Global Map of Lipid-Binding Proteins and Their Ligandability in Cells. Cell 161(7):1668-80, 2015. 
(110) Soethoudt, M., Stolze, S.C., Westphal, M.V., et al. Selective Photoaffinity Probe That Enables Assessment of Cannabinoid CB2 Receptor Expression and Ligand Engagement in Human Cells. Journal of the American Chemical Society 140(19):6067-75, 2018.

(111) Martín-Couce, L., Martín-Fontecha, M., Palomares, Ó., et al. Chemical Probes for the Recognition of Cannabinoid Receptors in Native Systems. Angew Chem Int Ed 51(28):6896-9, 2012.

(112) Soethoudt, M., Grether, U., Fingerle, J., et al. Cannabinoid CB2 receptor ligand profiling reveals biased signalling and off-target activity. Nature Communications 8:13958, 2017.

(113) Blankman, J.L., and Cravatt, B.F. Chemical Probes of Endocannabinoid Metabolism. Pharmacological Reviews 65(2):849-71, 2013.

(114) Petracca, R., Romeo, E., Baggelaar, M.P., et al. Novel activity-based probes for N-acylethanolamine acid amidase. Chemical Communications 53(86):11810-3, 2017.

(115) Eleftheriadis, N., Thee, S.A., Zwinderman, M.R.H., Leus, N.G.J., and Dekker, F.J. Activity-Based Probes for 15-Lipoxygenase-1. Angew Chem Int Ed:n/a-n/a, 2016.

(116) Marnett, L.J. Inflammation and Cancer: Chemical Approaches to Mechanisms, Imaging, and Treatment. The Journal of Organic Chemistry 77(12):5224-38, 2012.

(117) Kolb, H.C., Finn, M.G., and Sharpless, K.B. Click Chemistry: Diverse Chemical Function from a Few Good Reactions. Angew Chem Int Ed 40(11):2004-21, 2001.

(118) Isobe, Y., Kawashima, Y., Ishihara, T., Watanabe, K., Ohara, O., and Arita, M. Identification of Protein Targets of 12/15-Lipoxygenase-Derived Lipid Electrophiles in Mouse Peritoneal Macrophages Using OmegaAlkynyl Fatty Acid. ACS Chemical Biology, 2018.

(119) Robichaud, P.P., Poirier, S.J., Boudreau, L.H., et al. On the cellular metabolism of the click chemistry probe 19-alkyne arachidonic acid. Journal of Lipid Research 57(10):1821-30, 2016.

(120) Shelnut, E.L., Nikas, S.P., Finnegan, D.F., Chiang, N., Serhan, C.N., and Makriyannis, A. Design and synthesis of novel prostaglandin E2 ethanolamide and glycerol ester probes for the putative prostamide receptor(s). Tetrahedron Letters 56(11):1411-5, 2015.

(121) Finnegan, D.F., Shelnut, E.L., Nikas, S.P., Chiang, N., Serhan, C.N., and Makriyannis, A. Novel tail and head group prostamide probes. Bioorganic \& Medicinal Chemistry Letters 25(6):1228-31, 2015.

(122) Martín-Couce, L., Martín-Fontecha, M., Capolicchio, S., López-Rodríguez, M.L., and Ortega-Gutiérrez, S. Development of Endocannabinoid-Based Chemical Probes for the Study of Cannabinoid Receptors. Journal of Medicinal Chemistry 54(14):5265-9, 2011.

(123) Sonti, S., Duclos, R.I., Tolia, M., and Gatley, S.J. N-Docosahexaenoylethanolamine (synaptamide): Carbon-14 radiolabeling and metabolic studies. Chemistry and Physics of Lipids 210:90-7, 2018.

(124) Peng, S., Okeley, N.M., Tsai, A.-L., Wu, G., Kulmacz, R.J., and van der Donk, W.A. Synthesis of Isotopically Labeled Arachidonic Acids To Probe the Reaction Mechanism of Prostaglandin H Synthase. Journal of the American Chemical Society 124(36):10785-96, 2002.

(125) van der Donk, W.A., Tsai, A.-L., and Kulmacz, R.J. The Cyclooxygenase Reaction Mechanism. Biochemistry 41(52):15451-8, 2002. 
Table 1 -Recently identified oxidized metabolites of EPEA and DHEA, including the converting enzyme, receptor affinities and biological effects.

\begin{tabular}{|c|c|c|c|c|}
\hline Compound name and structure & $\begin{array}{l}\text { Enzymatic } \\
\text { product }\end{array}$ & $\begin{array}{l}\text { Binding } \\
\text { to } C B_{1} \text { or } \\
C B_{2}\end{array}$ & Biological activity & Reference \\
\hline $\begin{array}{c}\text { OH } \\
\text { 10,17-diHDHEA }\end{array}$ & $\begin{array}{c}\text { 15-LOX } \\
\text { metabolite of } \\
\text { DHEA (in } \\
\text { isolated } \\
\text { human PMN } \\
\text { cells and } \\
\text { mouse brain } \\
\text { tissue) }\end{array}$ & $\begin{array}{c}\mathrm{CB}_{2} \\
\text { agonist, } \\
\text { weak } \mathrm{CB}_{1} \\
\text { agonist }\end{array}$ & $\begin{array}{c}\text { Stop PMN } \\
\text { chemotaxis. Block } \\
\text { PAF stimulated } \\
\text { formation of } \\
\text { platelet-leukocyte } \\
\text { aggregates. }\end{array}$ & 76 \\
\hline $15-\mathrm{H}$ & $\begin{array}{l}\text { 15-LOX } \\
\text { metabolite of } \\
\text { DHEA (in } \\
\text { isolated } \\
\text { human PMN } \\
\text { cells) }\end{array}$ & $\begin{array}{c}\mathrm{CB}_{2} \\
\text { agonist, } \\
\text { weak } \mathrm{CB}_{1} \\
\text { agonist }\end{array}$ & $\begin{array}{c}\text { Block PMN } \\
\text { transmigration. } \\
\text { Block PAF stimulated } \\
\text { formation of } \\
\text { platelet-leukocyte } \\
\text { aggregates. Protects } \\
\text { ischemia/reperfusion } \\
\text { second order } \\
\text { injuries from PMN } \\
\text { infiltration. } \\
\end{array}$ & 76 \\
\hline 13, & $\begin{array}{c}\text { CYP450 } \\
\text { metabolite of } \\
\text { DHEA } \\
\text { (Isolated } \\
\text { from lung } \\
\text { tissue in mice } \\
\text { injected } \\
\text { K7M2 } \\
\text { osteosarcoma } \\
\text { cells) } \\
\end{array}$ & $\begin{array}{c}\text { Not } \\
\text { determined }\end{array}$ & $\begin{array}{l}\text { Reduce cell viability } \\
\text { and induce } \\
\text { apoptosis and anti- } \\
\text { migrational activity } \\
\text { in tumour cells. }\end{array}$ & 78 \\
\hline 7,8-EDP-EA & $\begin{array}{l}\text { CYP450 } \\
\text { metabolite of } \\
\text { DHEA } \\
\text { (Isolated } \\
\text { from lung } \\
\text { tissue in mice } \\
\text { injected } \\
\text { K7M2 } \\
\text { osteosarcoma } \\
\text { cells) }\end{array}$ & $\begin{array}{c}\text { Not } \\
\text { determined }\end{array}$ & $\begin{array}{l}\text { Reduce cell viability } \\
\text { and induce } \\
\text { apoptosis and anti- } \\
\text { migrational activity } \\
\text { in tumour cells. }\end{array}$ & 78 \\
\hline 10,11-EDP-EA & $\begin{array}{l}\text { CYP450 } \\
\text { metabolite of } \\
\text { DHEA } \\
\text { (Isolated } \\
\text { from lung } \\
\text { tissue in mice } \\
\text { injected } \\
\text { K7M2 } \\
\text { osteosarcoma } \\
\text { cells) } \\
\end{array}$ & $\begin{array}{c}\mathrm{CB}_{1} \text { and } \\
\mathrm{CB}_{2} \\
\text { agonist }\end{array}$ & $\begin{array}{l}\text { Reduce cell viability } \\
\text { and induce } \\
\text { apoptosis and anti- } \\
\text { migrational activity } \\
\text { in tumour cells. } \\
\text { Anti-angiogenic } \\
\text { effects. }\end{array}$ & 78 \\
\hline $\begin{array}{c}\text { O } \\
9,20 \text {-EDP-EA }\end{array}$ & $\begin{array}{l}\text { CYP450 } \\
\text { metabolite of } \\
\text { DHEA } \\
\text { (CYP2J2, } \\
\text { main CYP in } \\
\text { human brain } \\
\text { and heart) }\end{array}$ & $\begin{array}{l}\mathrm{CB}_{1} \text { and } \\
\mathrm{CB}_{2} \\
\text { agonist } \\
\text { (higher } \\
\text { preference } \\
\text { for } \mathrm{CB}_{2} \text { ) }\end{array}$ & $\begin{array}{l}\text { Inhibit IL-6 cytokine } \\
\text { and NO production, } \\
\text { and stimulate IL-10 } \\
\text { production in LPS } \\
\text { stimulated BV-2 } \\
\text { microglia, anti- } \\
\text { angiogenic and } \\
\text { vasodilatory effects }\end{array}$ & 77 \\
\hline
\end{tabular}




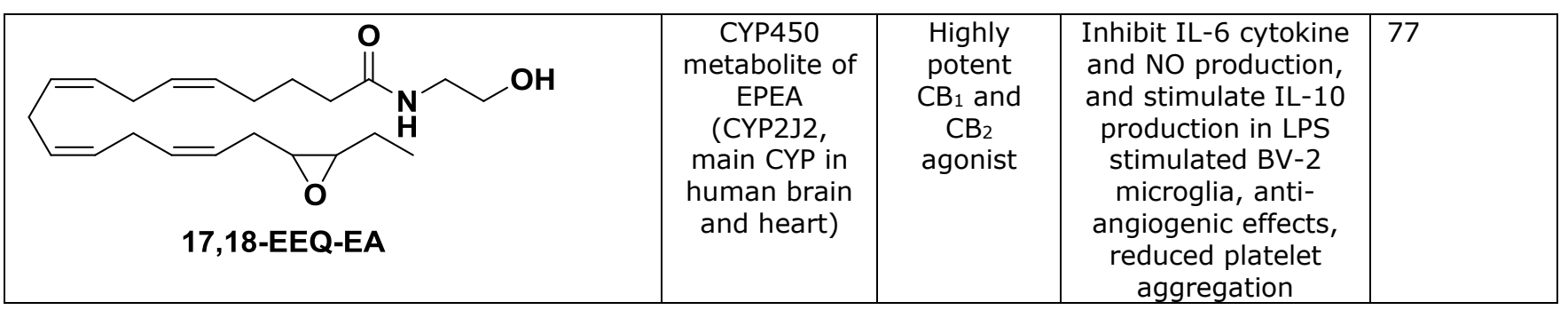


<smiles>CC/C=C\C/C=C\C/C=C\CCCCCCC(=O)O</smiles>

Linolenic acid (18:3n-3) (ALA)<smiles>CC/C=C\C/C=C\C/C=C\C/C=C\C/C=C\CCC(=O)O</smiles>

Eicosapentaenoic acid (20:5n-3) (EPA)<smiles>CC/C=C\C/C=C\C/C=C\CCCCCC(=O)O</smiles>

Docosapentaenoic acid (22:5n-3) (DPA)<smiles>CC/C=C\C/C=C\C/C=C\C/C=C\CCCCC(=O)O</smiles>

Stearidonic acid (18:4n-3) (SDA)<smiles>CC/C=C\C/C=C\C/C=C\C/C=C\CCCCCC(=O)O</smiles>

Eicosatetraenoic acid (20:4n-3) (ETA)<smiles>CC/C=C\C/C=C\C/C=C\C/C=C\C/C=C\C/C=C\CC(=O)O</smiles>

Docosahexaenoic acid (22:6n-3)

(DHA)

Figure 1 - Chemical structures of the main n-3 LC PUFAs.

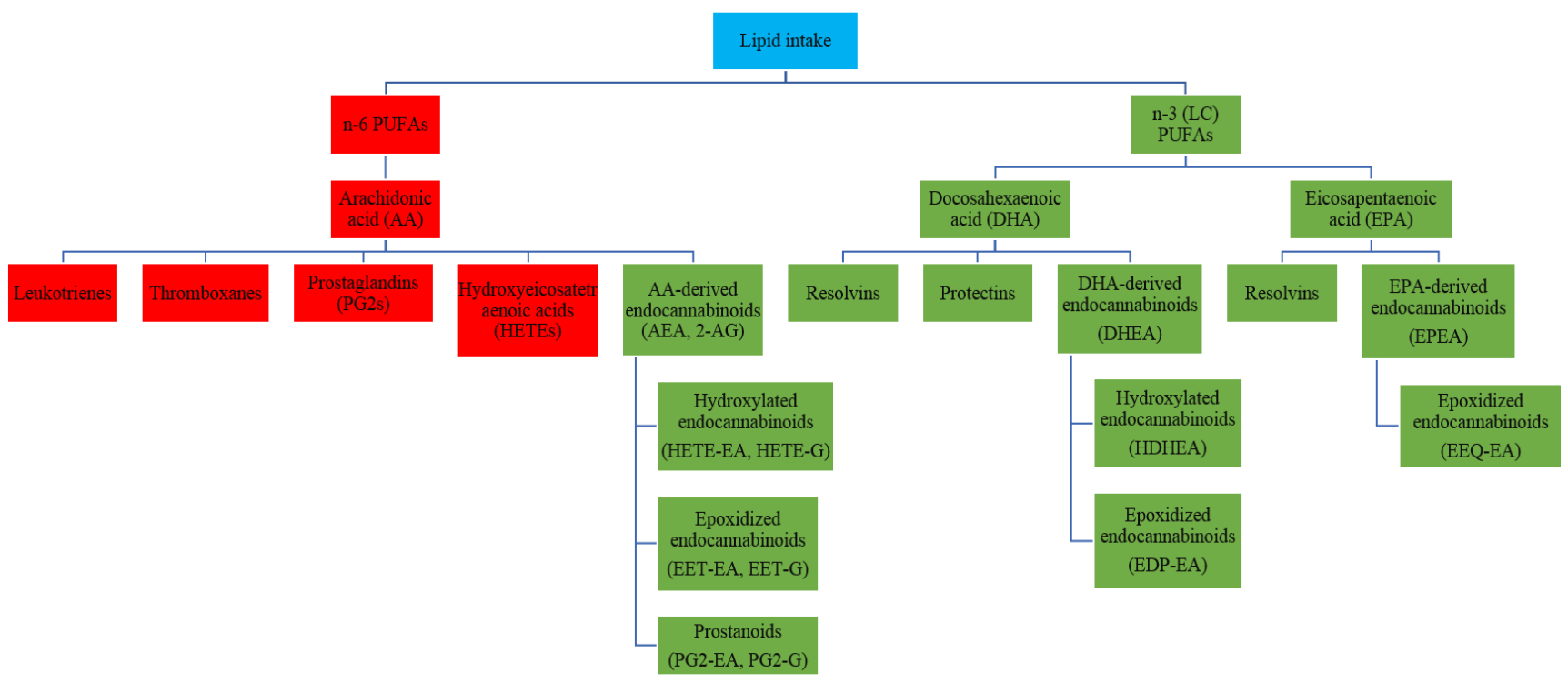

Figure 2 - Overview of lipid profile and lipid metabolism. In red are the suggested pro-inflammatory regulators, in green the proposed less pro- or anti-inflammatory regulators. Changes in lipid intake can change the lipid profile in the body, which in turn may reduce pro-inflammatory responses and/or downregulate inflammatory processes. 


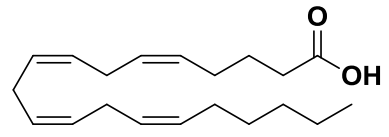

Arachidonic acid (20:4n-6)

(ARA)

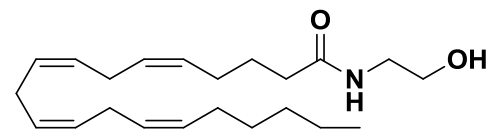

$\mathrm{N}$-Arachidonoylethanolamine (AEA)

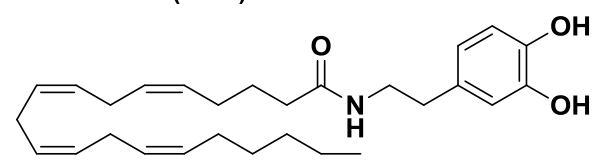

N-Arachidonoyldopamine (NADA)<smiles>CCCCC/C=C\C/C=C\C/C=C\C/C=C\CCCC(=O)OC(CO)CO</smiles>

N-Arachidonoylglycerol (2-AG)<smiles>CCCCC/C=C\C/C=C\CCCC(=O)NCC(=O)O</smiles>

N-Arachidonoylglycine (NAGIy)<smiles>CCCCCCCCCCCCCCCC(=O)NCCO</smiles>

Palmitoylethanolamine (PEA)<smiles>CCCCCCCC/C=C/CCCCCCCC(=O)NCCO</smiles>

Oleoylethanolamine (OEA)<smiles>CC/C=C\C/C=C\C/C=C\C/C=C\C/C=C\CCC(=O)NCCO</smiles>

Eicosapentaenoylethanolamine (EPEA)

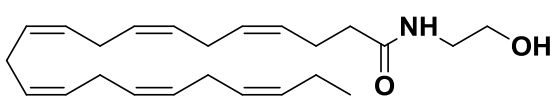

Docosahexaenoylethanolamine (DHEA)

Figure 3 - Chemical structures of well-known endocannabinoids and structurally related molecules. This family of lipids shows variation in both the lipid backbone as well as in the conjugate (e.g. glycerol, dopamine, ethanolamine, amino acid residues etc.). 


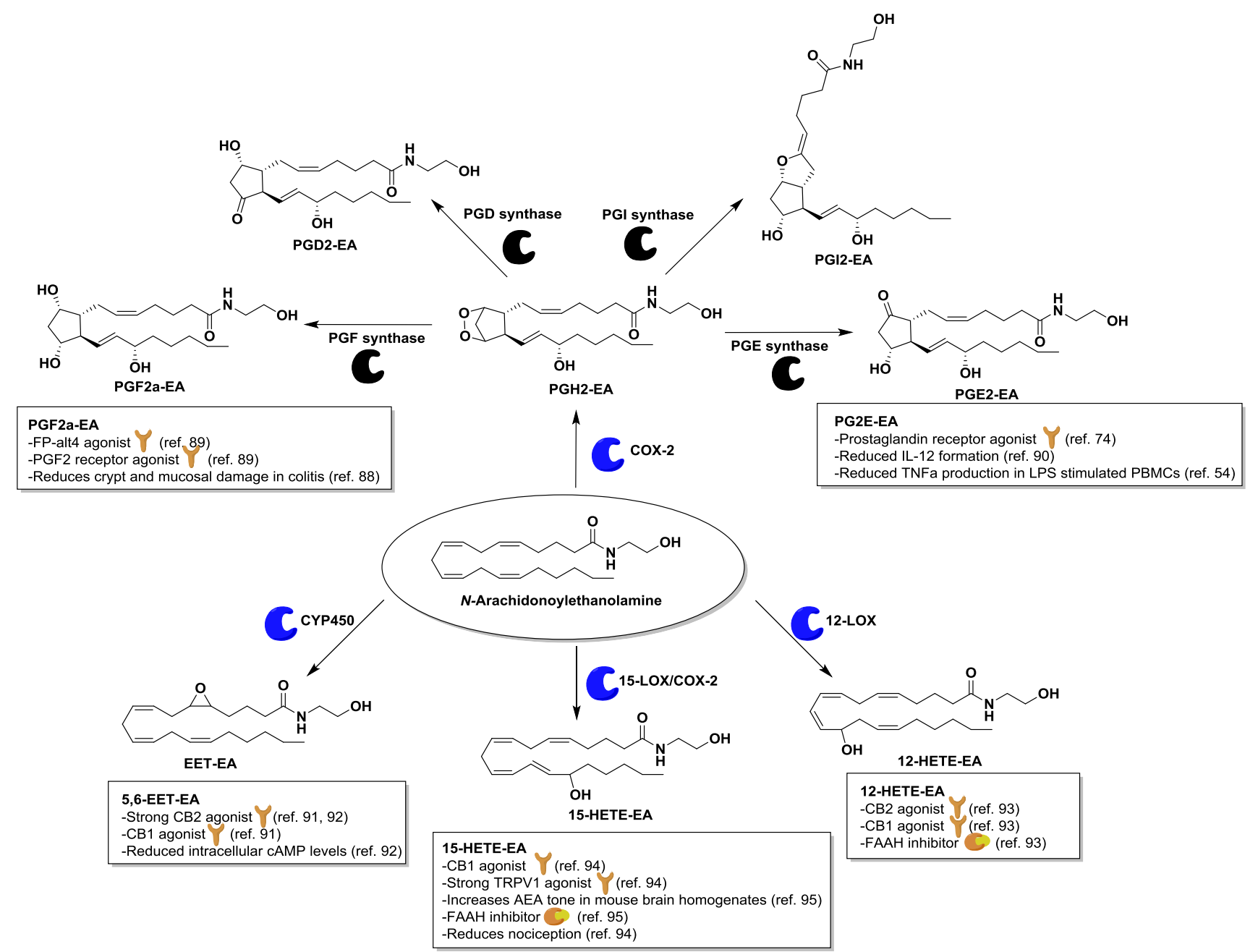

Figure 4 - Known metabolites of $N$-Arachidonoylethanolamide by COX, LOX and CYP450 enzymes, their main receptor affinities, and biological effects. 


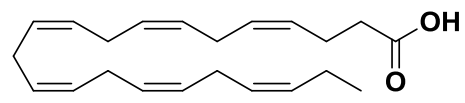

Docosahexaenoic acid
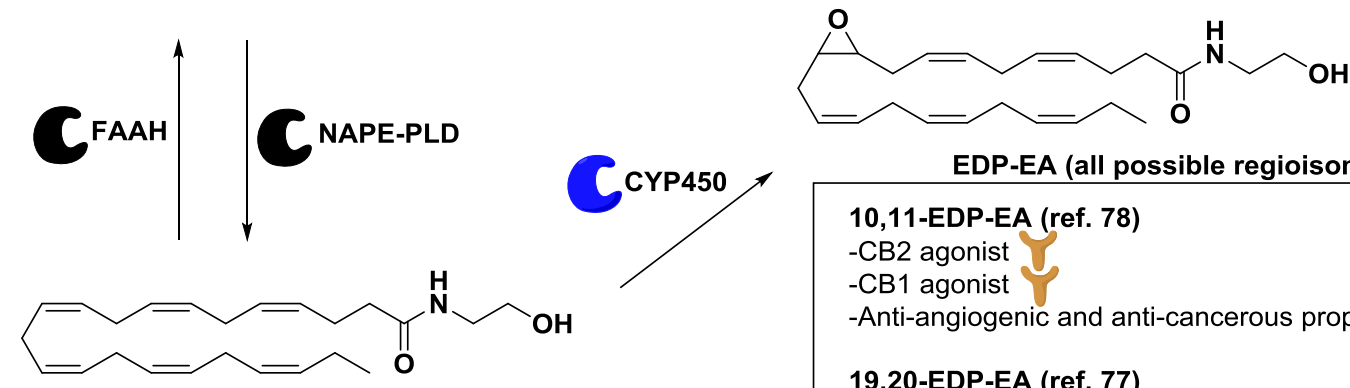

EDP-EA (all possible regioisomers have been identified)

Docosahexaenoyl ethanolamide
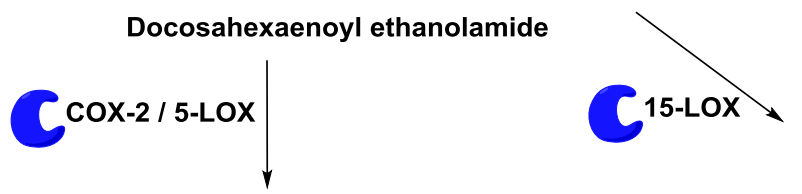

10,11-EDP-EA (ref. 78)

-CB2 agonist

-CB1 agonist

-Anti-angiogenic and anti-cancerous properties

19,20-EDP-EA (ref. 77)

-CB2 agonist

-Inhibit IL-6 and NO production

-Anti-angiogenic and vasodilatory effects

-Anti-proliferative in HNSCC cells (ref. 104)

-Anti-inflammatory in RAW264.7 cells (ref. 70)

-Product identification unknown

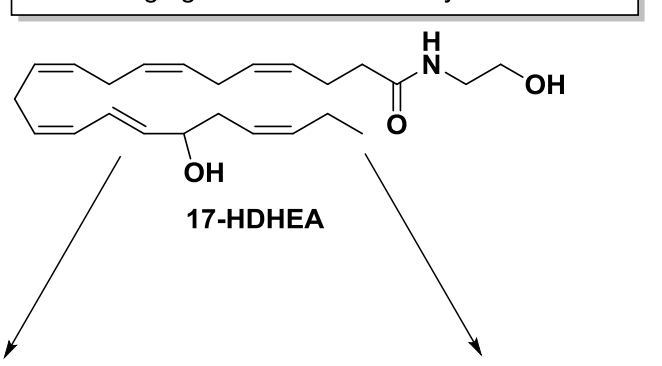

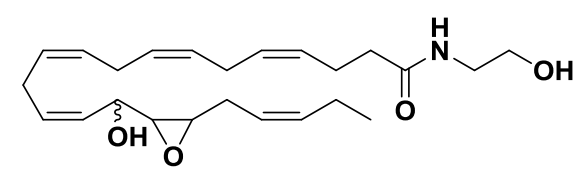

15-HEDPHEA

15-HEDPHEA (ref. 76)
-CB2 agonist
-Protects lung PMN infiltration
-Block platelet leukocyte aggregation

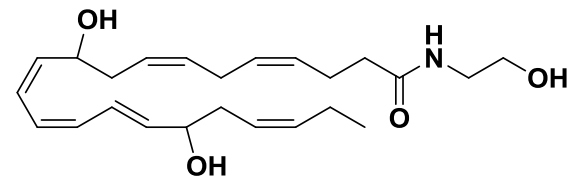

10,17-diHDHEA

10,17-diHDHEA (ref.76)

-CB2 agonist

-Block platelet leukocyte aggregation

Figure 5 - Metabolism of DHA into DHEA and subsequent further metabolism by CYP450 and 15-LOX into various hydroxylated or epoxidized metabolites. 


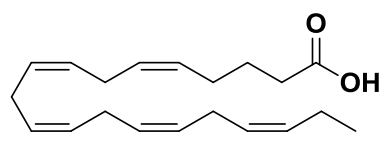

Eicosapentaenoic acid

(EPA)

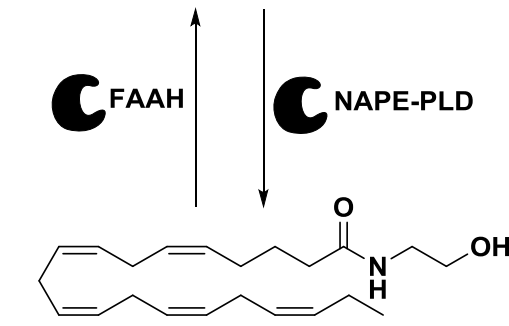

Eicosapentaenoylethanolamine (EPEA)

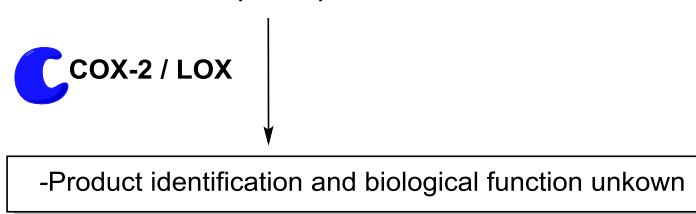

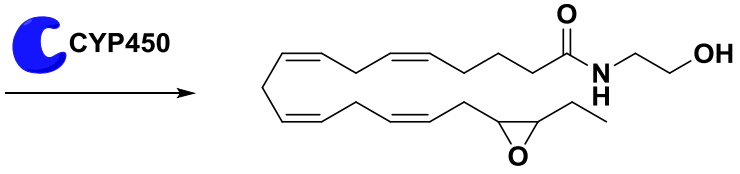

EEQ-EA (all possible regioisomers have been identified)

17,18-EDP-EA (ref. 77)

-CB2 agonist

-CB1 agonist

-Anti-angiogenic effect

-Inhibit platelet aggregarion

-Reduction in anti-inflammatory cytokines

Figure 6 - Metabolism of EPA into EPEA and subsequent further metabolism by CYP450 into various epoxidized metabolites. 


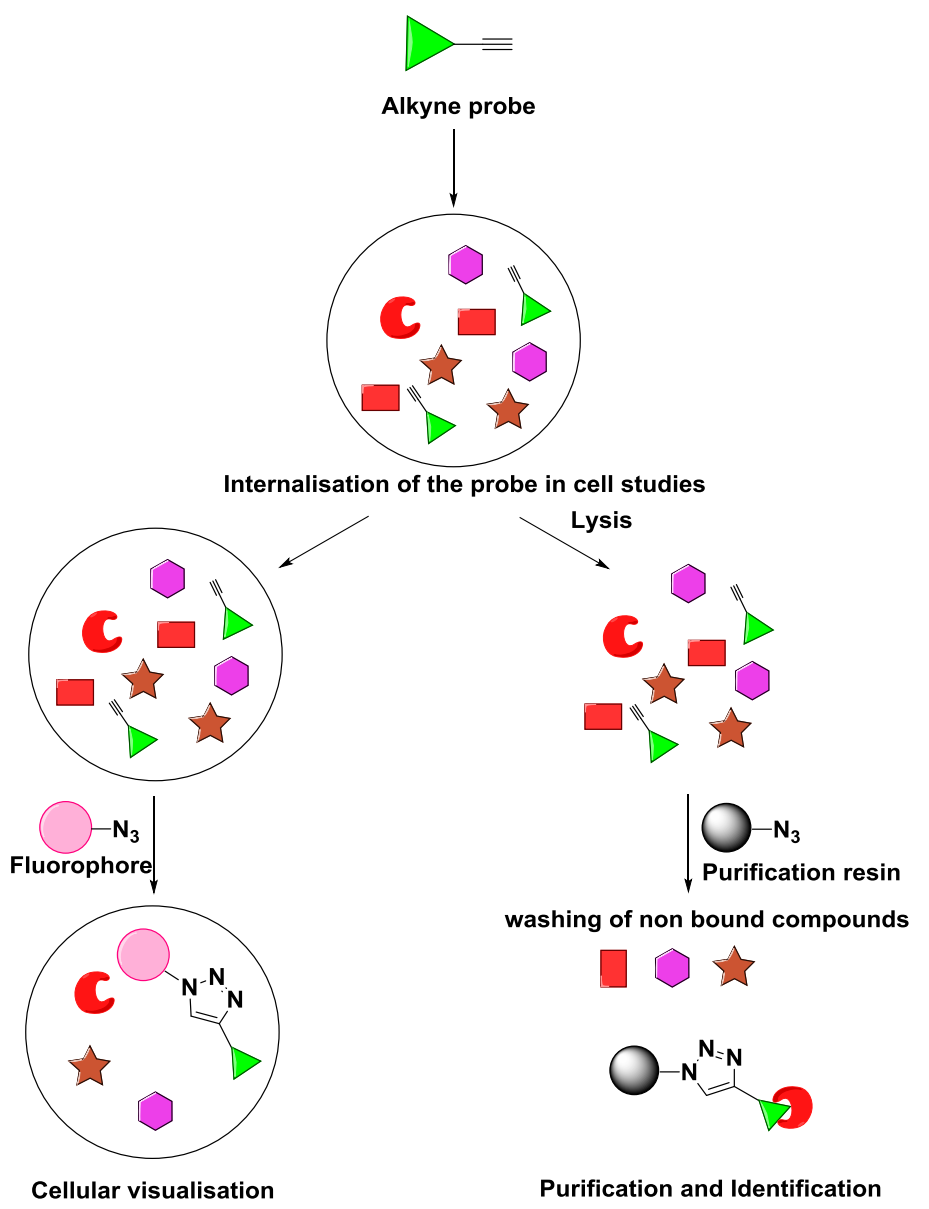

Figure 7 - Overview of two uses of alkyne probes to study the localisation of the molecule of interest with a detectable marker (often a fluorophore), or to study the molecular targets (mostly proteins) of the molecule of interest by clicking the probe to purification resins. 
<smiles>C#CCCC/C=C\C/C=C\C/C=C\CCCC(=O)O</smiles>

AA-A<smiles></smiles>

AEA-DA<smiles>C#CCCC/C=C\C/C=C\C/C=C\CCCC(=O)NCCC1(C)N=N1</smiles>

AA-DA

Figure 8 - Alkyne probes of arachidonic acid and anandamide (AEA). AA-A is an 19-alkyne arachidonic acid probe $^{118}$, AEA-DA is an 19-alkyne arachidonoyl ethanolamide probe with a diazirine photo-crosslinker at C16 ${ }^{109}$, and AA-DA is an 19-alkyne arachidonoyl probe with a diazirine conjugate group resembling the ethanolamine ${ }^{109}$.

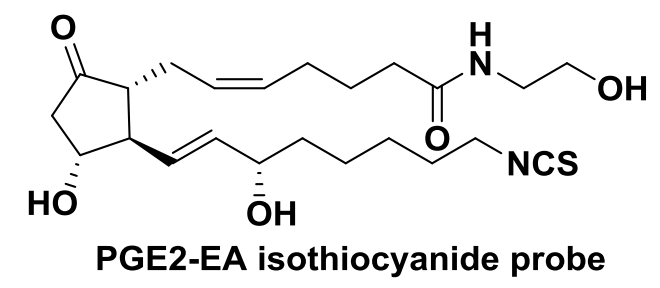<smiles>CCCCCCC(=O)OC(CO)COC(=O)C(=S)NC(=O)CCCC[C@H]1SC[C@@H]2NC(=O)N[C@@H]21</smiles>

\section{PGE2-G biotinlylated probe}

Figure 9 - PGE2-EA and PGE2-G probes used to study the interactions of PGE2-EA and PGE2-G with CB receptors. The PGE2-EA probe was described in ${ }^{120}$, and the PGE2-G probe in ${ }^{122}$. 
